\title{
COMPARISON OF CYLINDRICAL AND NON- CYLINDRICAL GRAIN INTERNAL BALLISTIC BEHAVIOR OF HYBRID ROCKET ENGINES AND SOLID ROCKET MOTORS
}

\author{
By \\ Zhiliu Lu \\ B.Eng., Aerospace Engineering, Northwestern Polytechnical University (2014)
}

A thesis

presented to Ryerson University

in partial fulfilment of the

requirements for the degree of

Master of Applied Science

in the Program of

Aerospace Engineering

Toronto, Ontario, Canada, 2017

CZhiliu Lu 2017 


\section{Author's Declaration}

\section{AUTHOR'S DECLARATION FOR ELECTRONIC SUBMISSION OF A THESIS}

I hereby declare that I am the sole author of this thesis. This is a true copy of the thesis, including any required final revisions, as accepted by my examiners.

I authorize Ryerson University to lend this thesis to other institutions or individuals for the purpose of scholarly research.

I further authorize Ryerson University to reproduce this thesis by photocopying or by other means, in total or in part, at the request of other institutions or individuals for the purpose of scholarly research.

I understand that my thesis may be made electronically available to the public. 


\title{
COMPARISON OF CYLINDRICAL AND NON- CYLINDRICAL GRAIN INTERNAL BALLISTIC BEHAVIOR OF HYBRID ROCKET ENGINES AND SOLID ROCKET MOTORS
}

\author{
Zhiliu Lu \\ Master of Applied Science, Aerospace Engineering, Ryerson University, Toronto (2017)
}

\section{Abstract}

Hybrid rocket engines (HREs) are a chemical propulsion system that nominally combine the advantages of liquid-propellant rocket engines (LREs) and solid-propellant rocket motors (SRMs). HREs in some cases can have a higher specific impulse and better controllability than SRMs, and lower cost and engineering complexity than LREs. For HREs and SRMs, both kinds of rocket engine employ a solid fuel grain, and the chosen grain configuration is a crucial point of their design. Different grain configurations have different internal ballistic behavior, which in turn can deliver different engine performance. A cylindrical grain design is a very common design for SRMs and HREs. A non-cylindricalgrain is a more complex grain configuration (than cylindrical) that has been used in many SRMs, and is also a choice for some HREs. However, while an HRE and an SRM can employ the same fuel grain configuration, the resulting internal ballistic behavior would not be expected to be the same. Pressure-dependent burning tends to dominate in SRMs, while axial flow-dependent burning tends to dominate in HREs. To help demonstrate in a more direct manner the influence of the differing combustion processes on the same fuel grain configuration used by an HRE and SRM, a number of internal ballistic simulations are undertaken for the present study. For the reference SRM cases looked 
at, an internal ballistic simulation program that has the capability of predicting head-end pressure and thrust as a function of time into a simulated firing is utilized for the present investigation; for the corresponding HRE cases, a simulation program is used to simulate the burning and flow process of these engines. For the present investigation, the two simulation programs are used to simulate the internal ballistic performance of various HREs and SRMs employing comparable cylindrical and noncylindrical fuel grain configurations. The predicted performance results, in terms of pressure and thrust, are consistent with expectations that one would have for both propulsion system types. 


\section{Acknowledgements}

First of all, I would like to thank my supervisor, Professor David Greatrix. Dr. Greatrix provided me the chance to be a member of his team and gave me guidance and support to explore the knowledge in my research area. As an international student and a young man first stepping into the field of propulsion, it would have been very hard for me to finish my master's program and research without advice and suggestions from Dr. Greatrix. His patience and enthusiasm encouraged me to overcome difficulties in my study. The great work done by Dr. Greatrix and other past researchers at Ryerson University on modelling the solid rocket motor burning rate and hybrid rocket engine regression rate and both propulsion systems' internal ballistics help me a lot in my research. Here, please allow me to express my respect and gratitude to all of you.

I want to thank my father, a major general in the China Air Force, who opened the door to the world of aerospace for me when I was still a little boy. Every time when I get confused, you are always there to help me find the correct direction. Mom, thank you for always reminding me about what I should do and what I still need to do better. Though both of you are far away from me and the only way to communicate with you is by video call, your encouragement and caring give me strength to study and live in this foreign country.

To my Uncle Eric and Cousin Jessica, thank you. You and your family helped me become familiar with this city and this country. It is so helpful to have some family members living in the same city when I am far away from home.

In the end, I want to thank all of my friends, especially my friends and teammates in Deka Ironwork. It is so good to have you guys by my side. 


\section{Table of Contents}

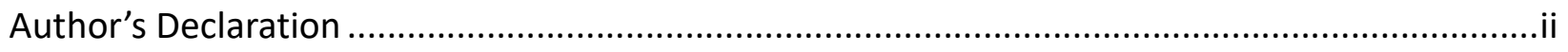

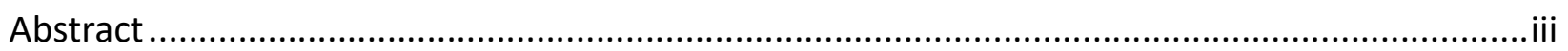

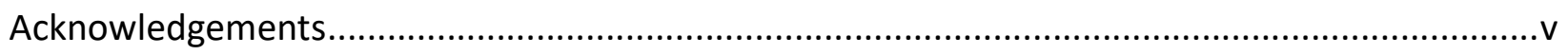

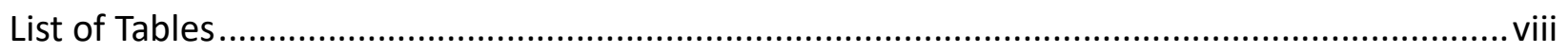

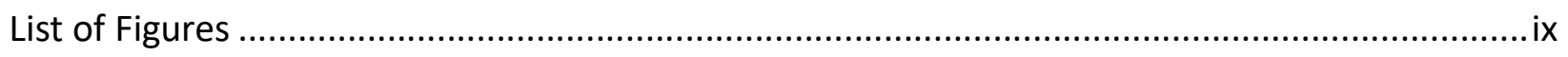

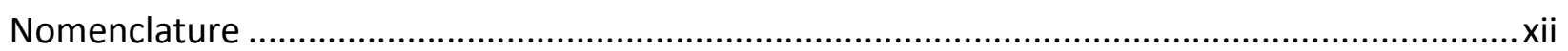

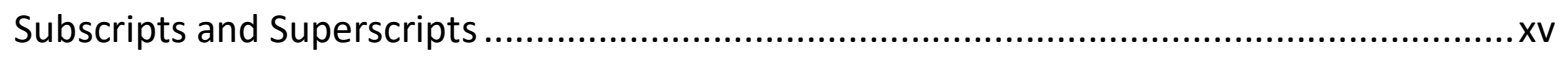

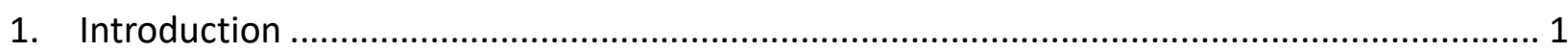

1.1. Some Background Knowledge Concerning Hybrid Rocket Engines........................... 3

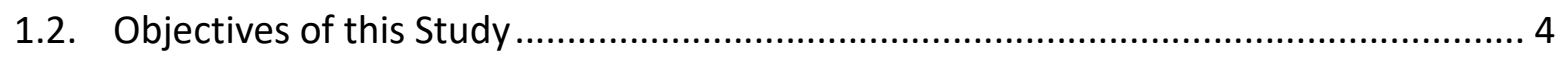

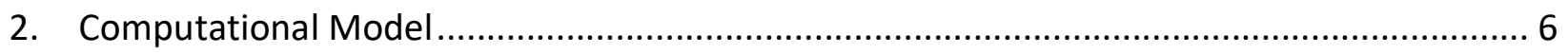

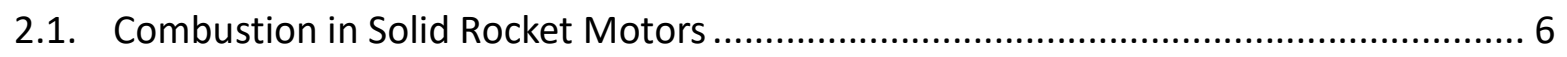

2.2. Combustion in Hybrid Rocket Engines ........................................................... 13

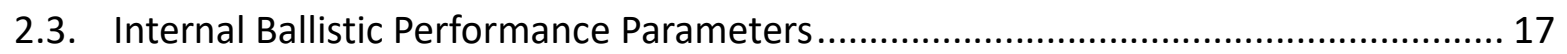

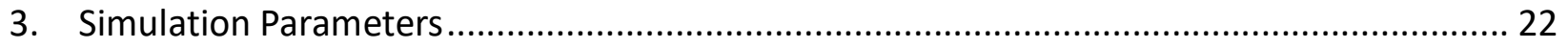

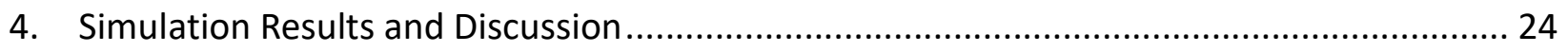

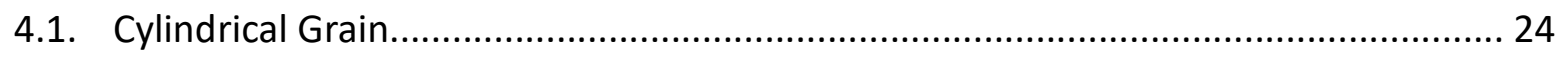


4.2. Star Grain

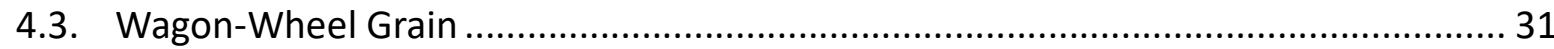

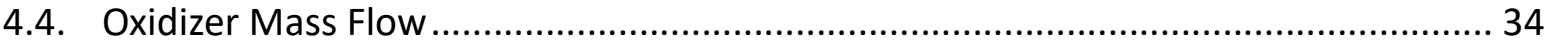

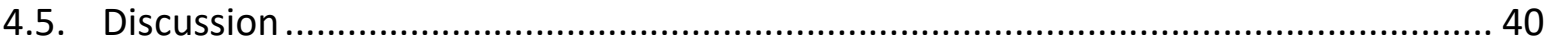

5. Conclusions and Recommendation for Future Work................................................... 43

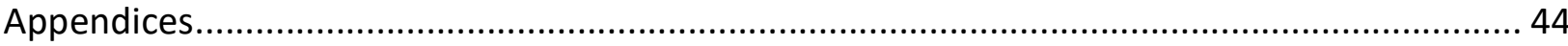

Appendix A: Star-Grain Cross-Sectional Geometry Analysis............................................ 44

Appendix B: Wagon-Wheel-Grain Cross-Sectional Geometry Analysis ..............................47

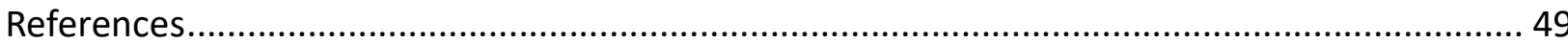




\section{List of Tables}

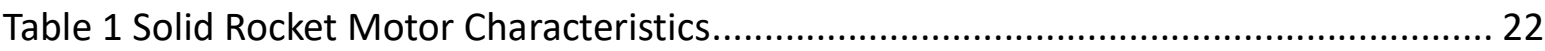

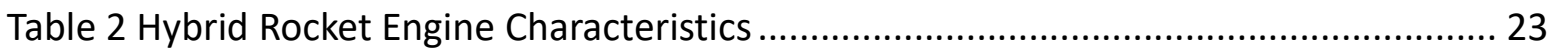

Table 3 Stoichiometric Length for Cylindrical-Grain HRE at Beginning and Ending of Firing under Different Oxidizer Mass Flows ........................................................ 36

Table 4 Stoichiometric Length for Star-Grain HRE at Beginning and Ending of Firing under Different Oxidizer Mass Flows ........................................................................... 38

Table 5 Stoichiometric Length for Wagon-Wheel-Grain HRE at Beginning and Ending of Firing under Different Oxidizer Mass Flow 39 


\section{List of Figures}

Figure 1 Dream Chaser Orbiter Ready for Ground Test .................................................. 2

Figure 2 Space-Ship-One after Its Successful Flight into Sub-orbit.................................... 2

Figure 3 Hybrid Rocket Engine Detail of Space-Ship-One ............................................ 3

Figure 4 the Scaled Composites Space-Ship-Two (Central Fuselage) Resting under Its Mothership, White Knight Two, inside a Hangar in Mojave, Ca., USA........................... 3

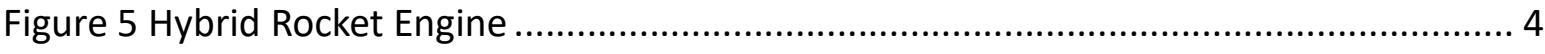

Figure 6 Diagram Illustrating Hybrid Rocket Engine Burning .......................................... 13

Figure 7 Predicted Pressure-Time Profile for Cylindrical-Grain SRM ................................. 25

Figure 8 Predicted Thrust-Time Profile for Cylindrical-Grain SRM ................................... 25

Figure 9 Predicted Pressure-Time Profile for Cylindrical-Grain HRE .................................. 26

Figure 10 Predicted Thrust-Time Profile for Cylindrical-Grain HRE ................................. 26

Figure 11 Predicted Stoichiometric Length-Time Profile for Cylindrical-Grain HRE ............ 27

Figure 12 Star-Grain Cross Section Profile (30 Pie Section) with Burn Back..................... 27

Figure 13 Predicted Pressure-Time Profile for Star-Grain SRM .................................... 28

Figure 14 Predicted Thrust-Time Profile for Star-Grain SRM ........................................ 29

Figure 15 Predicted Pressure-Time Profile for Star-Grain HRE ....................................... 29

Figure 16 Predicted Thrust-Time Profile for Star-Grain HRE......................................... 30

Figure 17 Predicted Stoichiometric Length-Time Profile for Star-Grain HRE..................... 30

Figure 18 Wagon-Wheel-Grain Cross Section Profile (22.5 $5^{\circ}$ Pie Section) with Burn 
Back

Figure 19 Predicted Pressure-Time Profile for Wagon-Wheel-Grain SRM 32

Figure 20 Predicted Thrust-Time Profile for Wagon-Wheel-Grain SRM 32

Figure 21 Predicted Pressure-Time Profile for Wagon-Wheel-Grain HRE 33

Figure 22 Predicted Thrust-Time Profile for Wagon-Wheel-Grain HRE 33

Figure 23 Predicted Stoichiometric Length-Time Profile for Wagon-Wheel-Grain HRE 34

Figure 24 Predicted Pressure-Time Profile for Cylindrical-Grain HRE under Different Oxidizer Mass Flows...... 35

Figure 25 Predicted Stoichiometric Length-Time Profile for Cylindrical-Grain HRE under Different Oxidizer Mass Flows 35

Figure 26 Predicted Pressure-Time Profile for Star-Grain HRE under Different Oxidizer Mass Flows 37

Figure 27 Predicted Stoichiometric Length-Time Profile for Star-Grain HRE under Different Oxidizer Mass Flows. 37

Figure 28 Predicted Pressure-Time Profile for Wagon-Wheel-Grain HRE under Different Oxidizer Mass Flows. 38

Figure 29 Predicted Stoichiometric Length-Time Profile for Wagon-Wheel-Grain HRE under Different Oxidizer Mass Flows. 39

Figure 30 Predicted Stoichiometric Length-Time Profile for the Three HREs under Same Oxidizer Mass Flows

Figure 31 Predicted Overall Oxidizer/Fuel Ratio-Total Oxidizer Mass Profile for the Three HREs 42

Figure 32 Star-Grain Cross Section (30 Pie Section) before Burning 44 
Figure 33 Star-Grain Cross Section ( $30^{\circ}$ Pie Section) in $2^{\text {nd }}$ Phase of Burning.

Figure 34 Star-Grain Cross Section ( $30^{\circ}$ Pie Section) in $3^{\text {rd }}$ Phase of Burning .... 46

Figure 35 Wagon-Wheel-Grain Cross Section (22.5 Pie Section) before Burning 47

Figure 36 Wagon-Wheel-Grain Cross Section (22.5 Pie Section) in $2^{\text {nd }}$ Phase of Burning 48

Figure 37 Wagon-Wheel-Grain Cross Section (22.5 Pie Section) in $3^{\text {rd }}$ Phase of Burning. 48 


\section{Nomenclature}

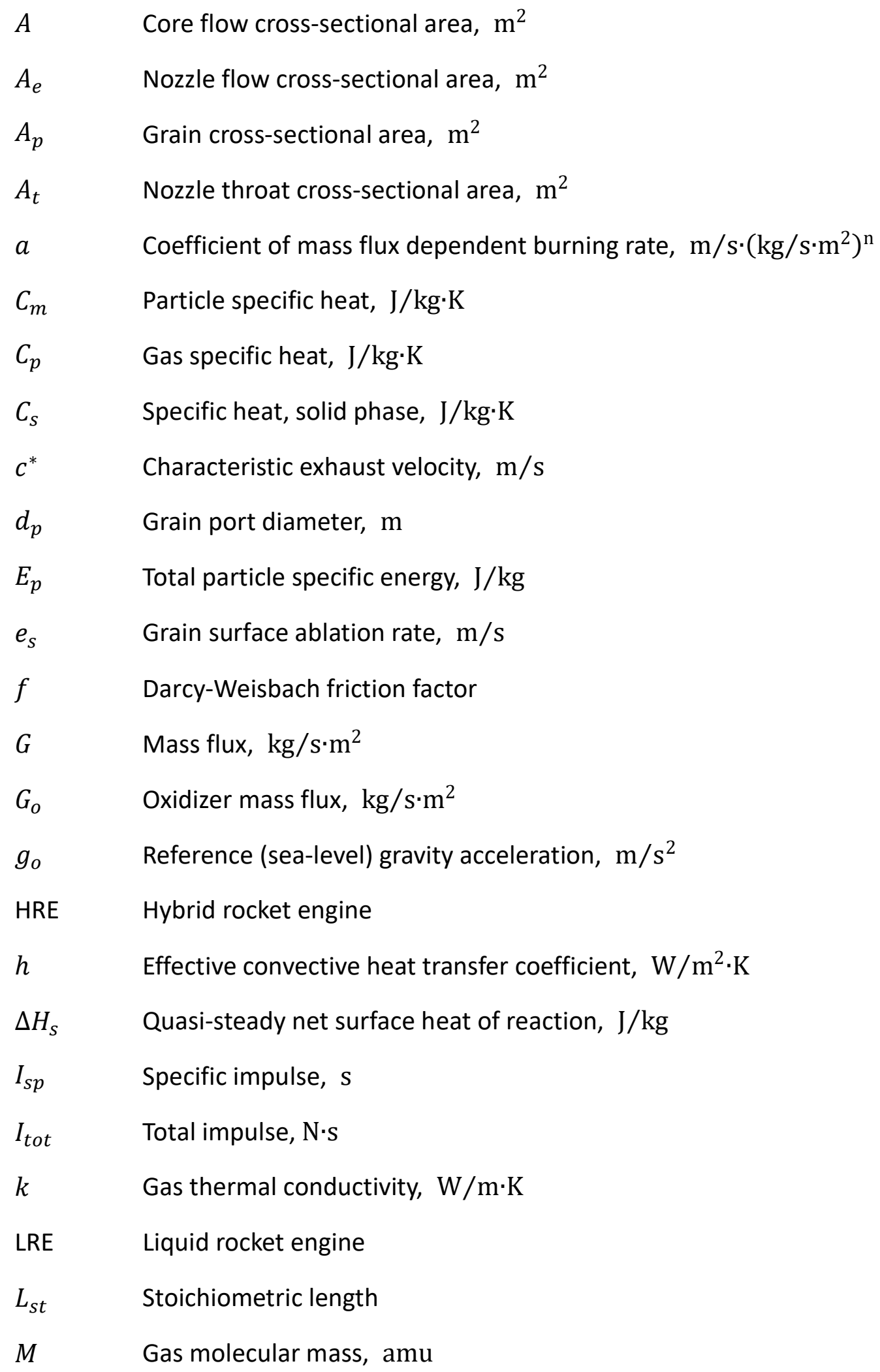




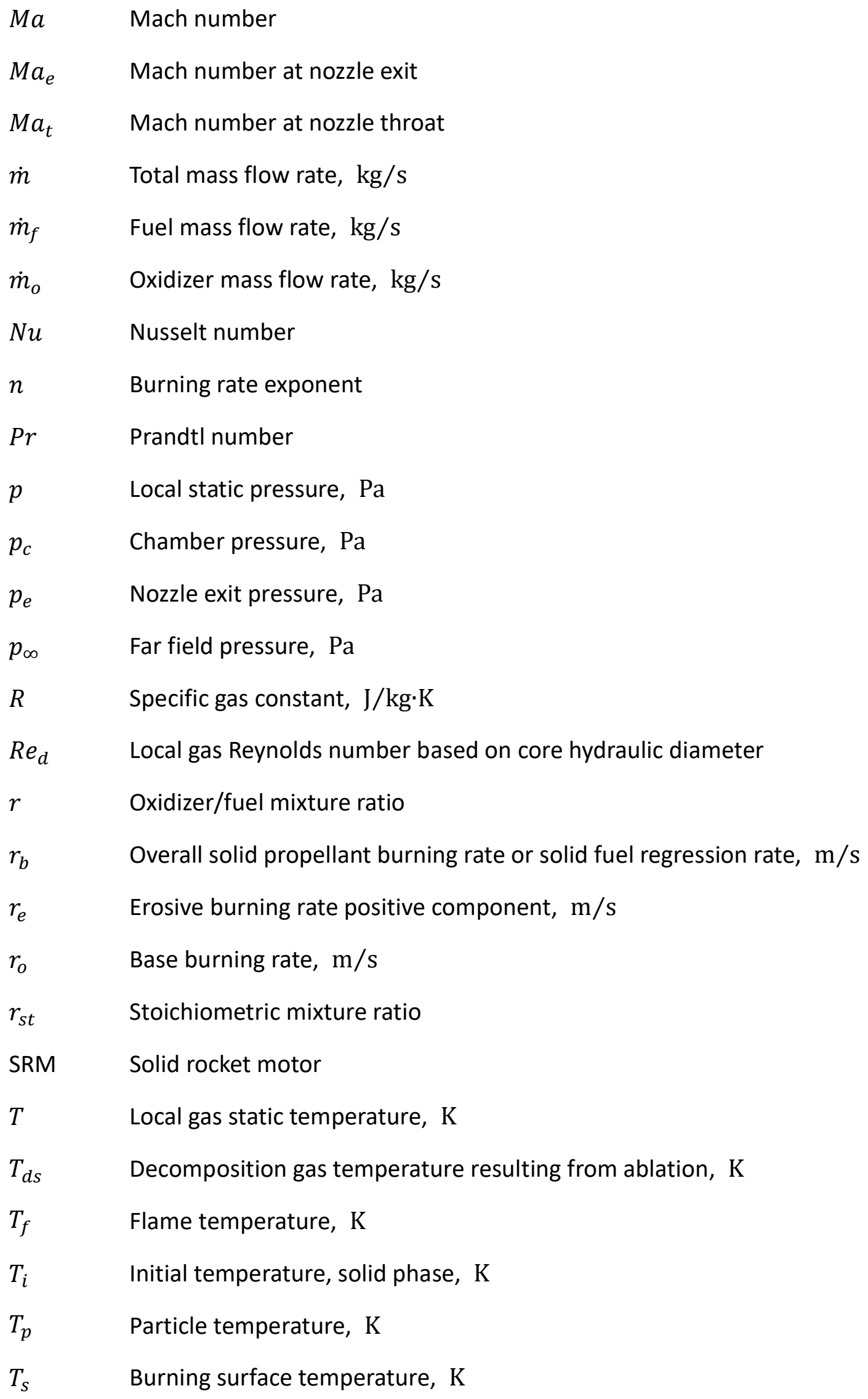


$u \quad$ Local axial gas velocity, $\mathrm{m} / \mathrm{s}$

$\alpha_{p} \quad$ Particle mass loading fraction of solid propellant

$\gamma \quad$ Ratio of specific heats of gas

$\varepsilon \quad$ Effective propellant surface roughness height, $\mathrm{m}$

$\delta_{o} \quad$ Reference combustion zone thickness, $\mathrm{m}$

$\mu \quad$ Absolute gas viscosity, $\mathrm{kg} /(\mathrm{m} \cdot \mathrm{s})$

$\rho_{S} \quad$ Density, solid phase, $\mathrm{kg} / \mathrm{m}^{3}$ 


\section{Subscripts and Superscripts}

$p \quad$ Subscript for particulate parameters

$x \quad$ Subscript for axial direction

comp Subscript for compressible flow regime

incomp Subscript for incompressible flow regime

* Superscript indicating zero-transpiration case 


\section{Introduction}

With the development of propulsion technology, a combination of features incorporated in liquid rocket engines (LREs) and solid rocket motors (SRMs) can be judiciously implemented into hybrid rocket engines (HREs). HREs have the ability to control thrust upon command by adjusting the oxidizer mass flow injected into the combustion chamber. HREs can also have a higher specific impulse than SRMs, which can help give HREs better mission flexibility and performance than SRMs. At the same time, HREs have lower engineering complexity than LREs. This means that HREs are easier and cheaper to manufacture. Another important advantage of HRE is the safety. Different to SRMs, the grain in HREs commonly only contain the fuel, while the oxidizer is loaded in the separate oxidizer tank. The separation of fuel and oxidizer mitigates the risk of accidental firing, while in pre-firing status, i.e., in storage.

Although the HRE has some advantages over SRMs and LREs, there are still some drawbacks in HRE design that need more research to enable improvements. The potential disadvantages include: compared with SRMs, HREs have lower fuel volumetric loading efficiency, lower chamber flame temperature, and larger fuel residuals. For a HRE and a SRM of similar scale, the HRE always have smaller fuel surface regression rates, which results in lower chamber pressures and thrusts. There are some problems that limit the performance of HREs, such as combustion instability and the dynamic (i.e., changing) fuel-oxidizer stoichiometric mixture ratio.

In the past two decades, our knowledge and understanding about hybrid rocket engines has improved, in part because of the research work undertaken at Ryerson University. An accurate fuel surface regression rate model has been developed, and a simulation program based on this model has been created at Ryerson University to predict the chamber pressure, thrust and stoichiometric length history for a variety of hybrid rocket engines with different grain configurations [1][2].

Despite the issues that need to be mitigated, the application of HREs for flight missions have grown. For example, the Dream Chaser Space System shown in Figure 1 is being developed by Sierra Nevada Corporation for NASA's Commercial Crew Integrated Capability (CCiCAP) Program. A hybrid 
rocket engine has been chosen to be the main engine for the orbiter vehicle of this system. SpaceShip-One, as shown in Figure 2 is an experimental air-launched rocket-powered space tourism aircraft with suborbital flight capability developed by Mojave Aerospace Ventures that also uses an HRE as the main engine (refer to Figure 3). The next generation space tourism vehicle Space-Ship-Two, shown in Figure 4, also employs an HRE as the main engine.

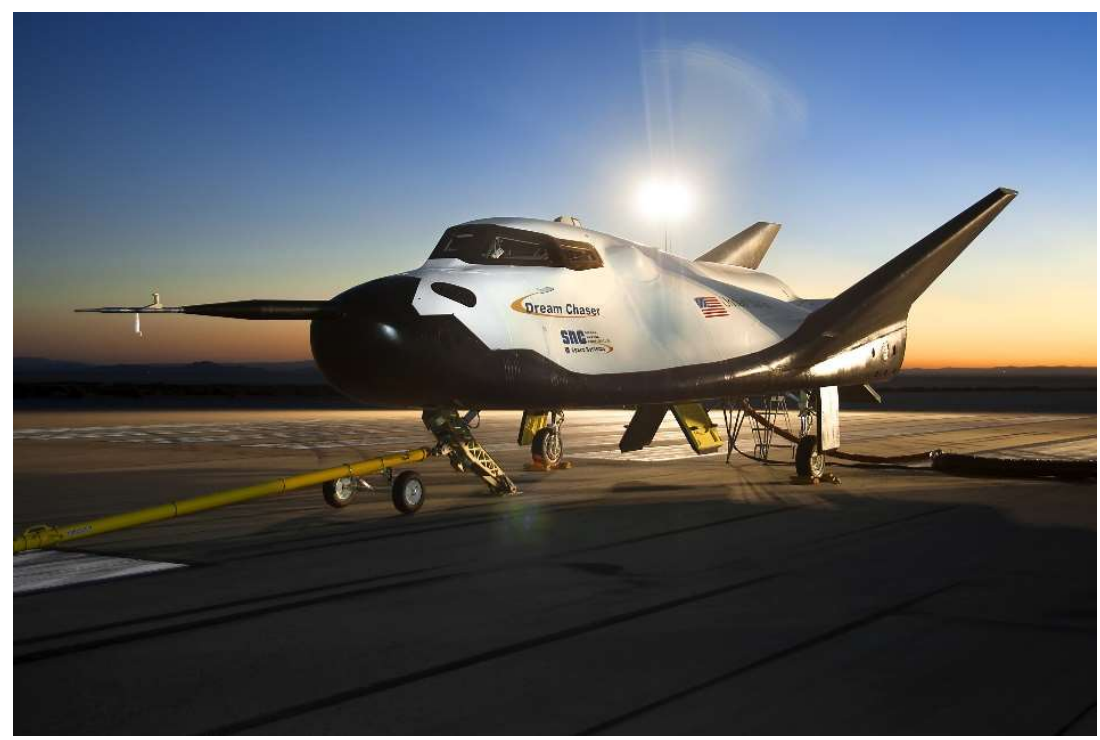

Figure 1 Dream Chaser Orbiter Ready for Ground Test

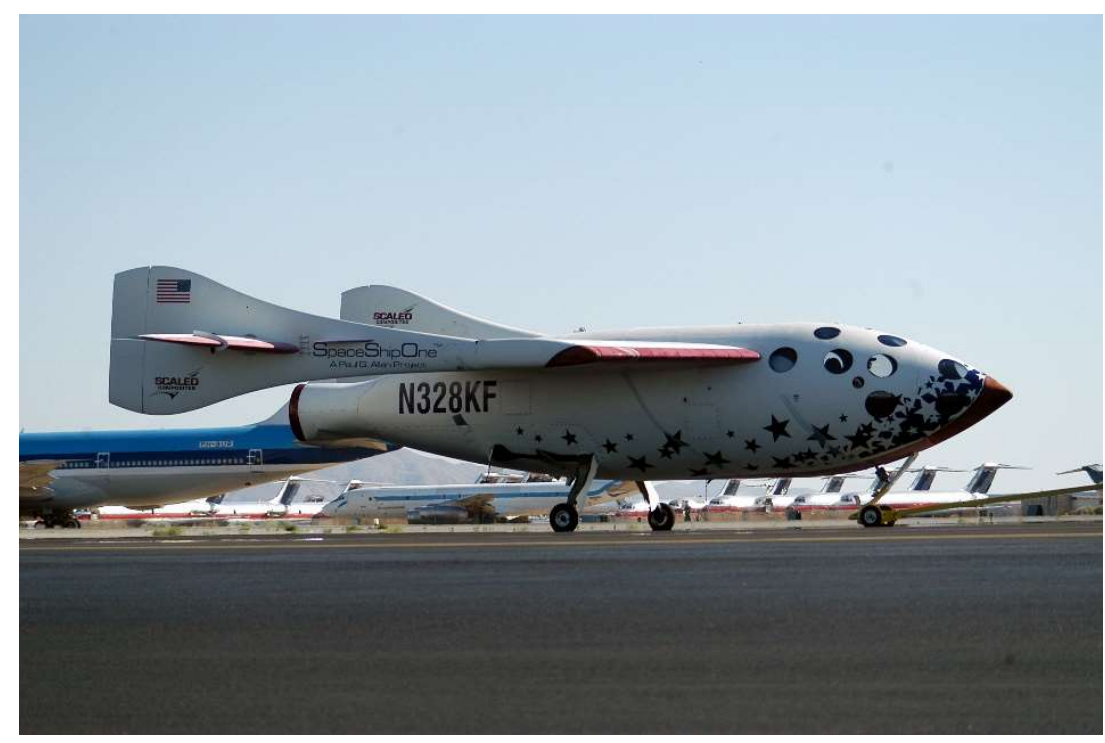

Figure 2 Space-Ship-One after Its Successful Flight into Sub-orbit (photo by D. Ramey Logan) 


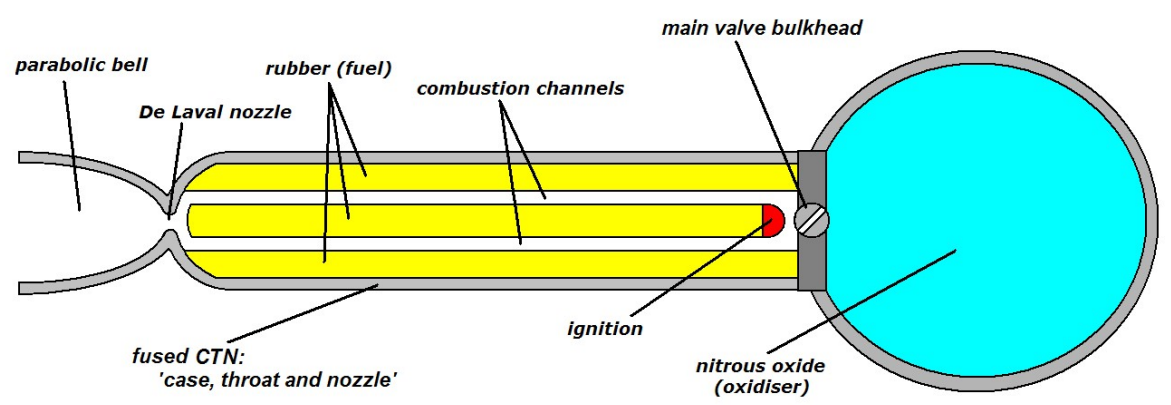

Figure 3 Hybrid Rocket Engine Detail of Space-Ship-One

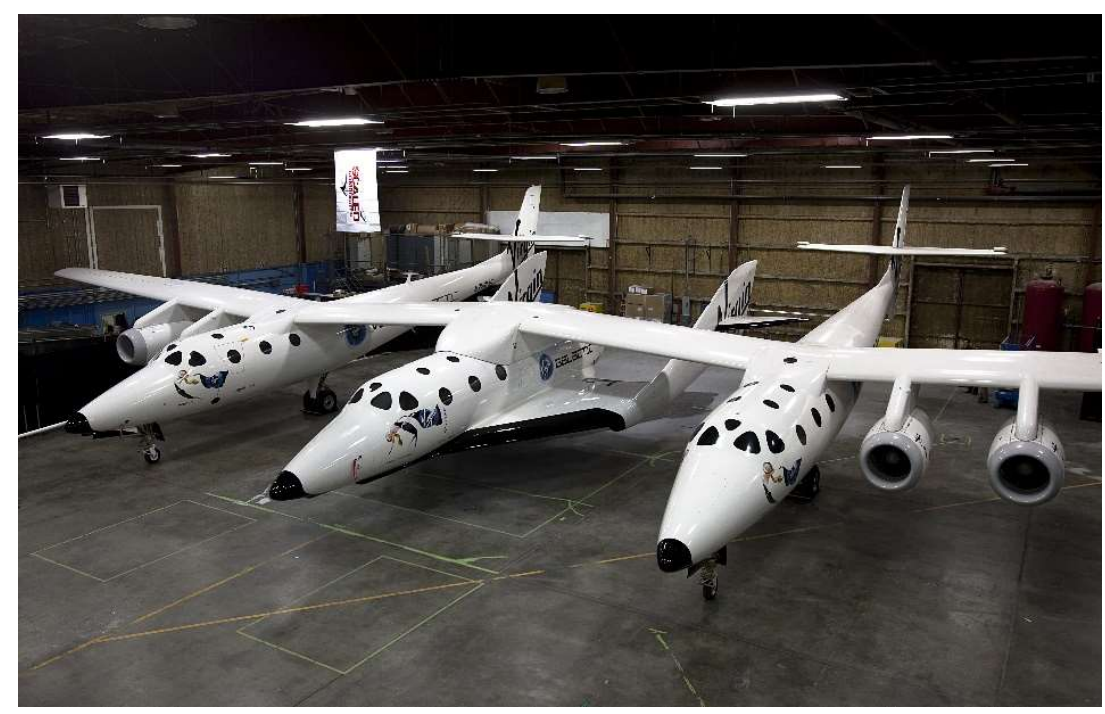

Figure 4 the Scaled Composites Space-Ship-Two (Central Fuselage) Resting under Its Mothership, White Knight Two, inside a Hangar in Mojave, Ca., USA

\subsection{Some Background Knowledge Concerning Hybrid Rocket Engines}

For hundreds of years, solid propellant (that contains fuel and oxidizer within it) was the only thrust source for rockets. This situation was changed because of the hard work of Robert Goddard in the 1920s. With the "lift off" of the first rocket using a liquid-propellant rocket engine, developed by Robert Goddard, the time for LRE usage had arrived. With several decades' development, now most launch vehicles in the world choose LREs as the main engine. SRMs are mainly used as the launch vehicle first-stage booster, sometimes as an upper-stage orbital insertion motor, and the main engine of small rockets and guided missiles for military applications. 
In the 1930 s, some engineers in Germany explored the idea of a propulsion system that combines some characteristics from solid rocket motors and liquid rocket engines, and made several prototype engines for test. This can be considered as the beginning of hybrid rocket engines. In the 1940s, the United States also started their early research and development of hybrid rocket engines. After decades of research and development, the HRE has become, arguably, a mature propulsion system.

Figure 5 provides a diagram of a conventional hybrid rocket engine. As shown in this figure, the HRE not only has a solid fuel grain similar to the propellant grain in SRMs, but also has an oxidizer tank, valve and injector that commonly appear in LREs.

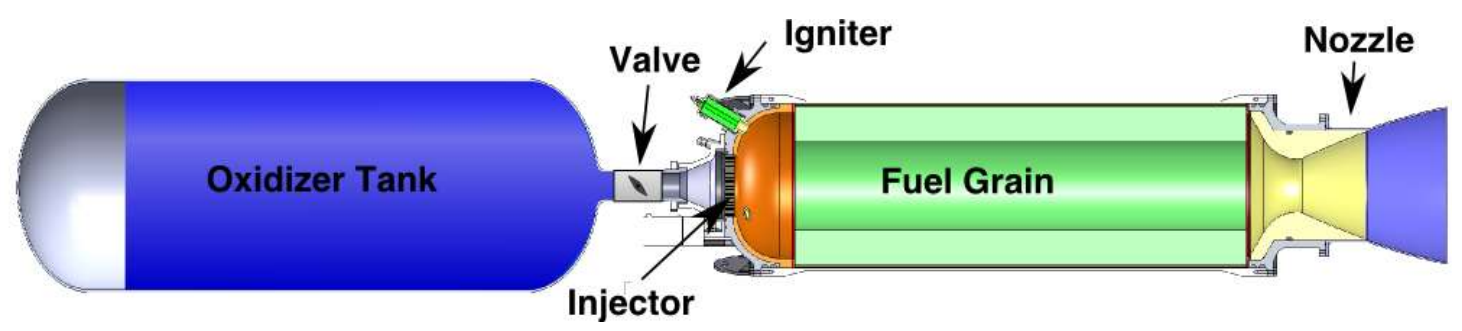

Figure 5 Hybrid Rocket Engine (by Jonny Dyer)

It should be noted that "grain" as expressed in this document is another term for charge. A charge is a solid chemical substance with pyrotechnic characteristics. Charges (fuel or propellant grains in the context of this study) are commonly liquid in origin, and solidified into a desired shape in a mold, or solidified in place in the motor casing. An expendable solid mandrel is used commonly to implement the central port shape, while the liquid chemical is hardening into a solid. The term "grain" in the present context is not meant to infer "a compaction of individual small grains into a larger solid mass".

\subsection{Objectives of this Study}

For SRMs, the solid propellant grain configuration is a critical aspect of its design. Grain configurations have a significant influence on the internal ballistic behavior of SRMs, which in turn sets the performance of these rocket motors. Similar to SRMs, an HRE's fuel grain configuration can also have an important impact on internal ballistic behavior and engine performance. However, 
because of the difference between SRMs and HREs in terms of operation, the same grain configuration will produce different internal ballistic behavior in these two propulsion systems, as will be made clear by the results of this study.

In the present computational study, the internal ballistic behaviors between SRMs and HREs that have nominally the same grain configuration are investigated. Three grain configurations are picked for simulation analysis: one is a cylindrical-grain design, and the other two designs are non-cylindricalgrain designs. All of the three designs are simulated in quasi-steady state simulation programs respectively for the internal ballistics of SRMs and HREs. It should be noted that both simulation programs have in the past shown good agreement with experimental firing data for a number of cases [1]-[7]. The programs can generate profiles such as chamber pressure vs. time and thrust vs. time to help with performance comparison and analysis. The fuel grain is nominally the same configuration for the given SRM and HRE pairing being looked at. However, because of the different types of solid propellant or fuel/oxidizer combination and respective combustion mechanism, parameters like grain length, fuel density and propellant specific heat cannot necessarily be kept the same for a grain design when being applied to one or the other propulsion systems. 


\section{Computational Model}

The evaluation and prediction of internal ballistic combustion and flow behavior for solid rocket motors and hybrid rocket engines relies on accurately modelling propellant burning rate (fuel surface regression rate). Estimating burning rate allows one in turn to predict the geometry change of the propellant/fuel grain, performance parameters such as chamber pressure and thrust, etc. Although there are some common points between SRMs and HREs, different burning rate models are needed for the two systems, given the different combustion mechanisms at play.

This chapter covers the equations that are necessary for estimating both propulsion systems' internal ballistic behavior parameters. Section 2.1 provides the equations for the solid rocket motor burning rate model and flow behavior equations used in the SRM simulation program. Section 2.2 provides the equations for the hybrid rocket motor engine fuel surface regression rate model and flow behavior equations used in the HRE simulation program. Section 2.3 provides the equations for estimating relevant internal ballistic performance parameters.

\subsection{Combustion in Solid Rocket Motors}

In the case of SRMs, the propellant burning rate mainly depends on pressure. Considering the flow-dependent erosive burning phenomenon that occasionally accompanies the base pressuredependent burning contribution, the overall burning rate $r_{b}$ of SRMs can be obtained through the equation shown below:

$$
r_{b}=r_{o}+r_{e}
$$

In Eq. (1), the parameter $r_{o}$ stands for the base pressure-dependent component; this burning rate component can commonly be calculated via de St. Robert's law:

$$
r_{o}=C p^{n}
$$

where coefficient $C$ and exponent $n$ are distinctive to the particular solid propellant being 
employed, and $p$ is the local static pressure.

The other component $r_{e}$ in Eq. (1) is the positive erosive burning component. During SRM firing experiments over the years, flow-dependent augmentation on the base burning rate had been observed, which is the positive erosive burning that we know today. Positive erosive burning is a phenomenon caused by heightened convective heat transfer to the burning propellant surface engendering a reciprocating feedback from the gasification/combustion process [6]. Several approaches have been made to estimate the positive erosive burning component, such as the convective heat transfer model by Lenoir and Robillard [7]. However, the coefficients in the L-R model vary considerably in order to match up with the experimental firing data. Poor universality is not suitable for prediction [6]. Greatrix and Gottlieb [8] introduced a convective heat transfer feedback model for positive erosive burning. In this model, the positive erosive burning component can be estimated via:

$$
r_{e}=\frac{h\left(T_{F}-T_{S}\right)}{\rho_{s}\left[C_{s}\left(T_{S}-T_{i}\right)-\Delta H_{s}\right]}
$$

where $T_{F}$ is the flame temperature, $T_{S}$ is the burning surface temperature, $\rho_{S}$ is the propellant density, $C_{p}$ is the propellant specific heat, $T_{i}$ is the initial propellant temperature, and $\Delta H_{S}$ is the net surface heat release. The convective heat transfer coefficient $h$ can be calculated via an equation that comes from film theory (Greatrix and Gottlieb [8]; Mickley et al. [9]; Moffat and Kays [10]). Film theory assumes that the nominal one-dimensional flame height (a.k.a., height or depth of the effective combustion zone) above the propellant surface is low in comparison to the corresponding boundary-layer thickness. Based on this theory, the value for $h$ can be estimated via:

$$
h=\frac{\rho_{s} r_{b} C_{p}}{\exp \left(\frac{\rho_{s} r_{b} C_{p}}{h^{*}}-1\right)}
$$

In Eq. (4), $h^{*}$ is the convective heat transfer coefficient under zero transpiration. The vertical mass flow at the propellant grain surface can reduce the grain surface friction, which leads to the reduction of heat transfer to the grain surface. Because of this, in a transpired case, the heat transfer value is 
less than the non-transpired case. So, the convective heat transfer coefficient needs to be corrected based on the convective heat transfer coefficient under zero transpiration. The convective heat transfer coefficient under zero transpiration can be estimated via:

$$
h^{*}=\frac{k^{2 / 3} C_{p}^{1 / 3}}{\mu^{2 / 3}} \frac{G f^{*}}{8}
$$

where $f^{*}$ is the zero-transpiration Darcy-Weisbach friction factor. For fully developed turbulent flow, the zero-transpiration Darcy-Weisbach friction factor $f^{*}$ in equation above can be estimated via Colebrook's expression:

$$
\left(f^{*}\right)^{-1 / 2}=-2 \log _{10}\left[\frac{2.51}{\operatorname{Re}_{d}\left(f^{*}\right)^{1 / 2}}+\frac{\varepsilon / d_{p}}{3.7}\right]
$$

where $\varepsilon$ is the effective propellant surface roughness height, $R e_{d}$ is the Reynolds number, and $d_{p}$ is the propellant grain inner port diameter. For non-cylindrical grain design, one can use hydraulic diameter for $d_{p}$, which can be estimated via $4 A_{p} / s_{p}$, where $s_{p}$ is the peripheral distance around the core. For the developing flow, the zero-transpiration Darcy-Weisbach friction factor $f^{*}$ can be estimated from the following empirical expression as a function of axial distance $x$ from the motor's head end [11]:

$$
f^{*}=4\left[1.89-1.62 \log _{10}\left(\frac{\varepsilon}{x}\right)\right]^{-2.5}-7.04\left[1.89-1.62 \log _{10}\left(\frac{\varepsilon}{x}\right)\right]^{-3.5}
$$

Allowing for the compressibility effects on the friction factor under different values of local flow Mach number $M a_{\infty}$, the compressible-flow friction factor can be calculated via:

$$
f_{\text {comp }}=f_{\text {incomp }} /\left[1+\operatorname{Pr}^{1 / 3}\left(\frac{\gamma-1}{2}\right)\right] M a_{\infty}^{2}
$$

where $\operatorname{Pr}$ is the Prandtl number of the core gas flow.

In experiments, it has been observed on occasion that the burning rate drops a little bit below the expected value, at low flow speeds. This phenomenon is called negative erosive burning. 
According to Greatrix's research [12], this kind of reduction in burning rate is caused by a laminartype stretching or sliding of the effective combustion zone with the local core flow. This laminar effect would no longer exist with the increasing of turbulence above a certain threshold. In the present study, the influence of negative erosive burning will be considered. So, for lower axial flow speeds, the equation of overall burning rate can be changed into:

$$
r_{b}=\left.\frac{r_{b}}{r_{o}}\right|_{\delta_{r}} \cdot r_{o}+r_{e}
$$

When $f<f_{\text {lim }}$, via Greatrix's analysis, one can ascertain the burning rate ratio as follows:

$$
\left.\frac{r_{b}}{r_{o}}\right|_{\delta_{r}}=\cos \left[\tan ^{-1}\left(\frac{u_{e f f}}{v_{f}}\right)\right]=\cos \left[\tan ^{-1}\left(K_{\delta} \delta_{o}\left[1-\left(\frac{f}{f_{\lim }}\right)^{0.5}\right] \frac{\rho u_{\infty}}{\rho_{s} r_{o}}\right)\right]
$$

Here, $K_{\delta}$ is the shear layer coefficient, $\delta_{r}$ is the effective stretched combustion zone thickness under core flow, $f_{\text {lim }}$ is the limit friction factor, and the reference combustion zone thickness $\delta_{o}$ can be estimated as follows:

$$
\delta_{o}=\frac{k}{\rho_{s} r_{o} C_{p}} \cdot \ln \left[1+\frac{C_{p}\left(T_{F}-T_{S}\right)}{C_{s}\left(T_{S}-T_{i}\right)-\Delta H_{s}}\right]
$$

From film theory (Mickley et al. [9]; Moffat and Kays [10]), the friction factor $f$ can be calculated based on the $f^{*}$ value calculated earlier:

$$
f=8 \frac{\rho_{s} r_{b}}{G} /\left(\exp \left[\frac{8 \rho_{s} r_{b}}{G \cdot f^{*}}\right]-1\right)
$$

Combustion behavior analysis is just part of the internal ballistic analysis; flow behavior in the combustor should also be evaluated. When the Mach number of the flow over the propellant surface is at a relatively low level $(M a<0.2)$, the chamber pressure can be estimated directly via:

$$
p_{c}=\left\{\left[\frac{\gamma}{R T_{f}}\left(\frac{2}{\gamma+1}\right)^{\frac{\gamma+1}{\gamma-1}}\right]^{0.5} \frac{A_{t}}{\rho_{s} S C}\right\}^{\frac{1}{n-1}}
$$

Here, $C$ is the St. Robert coefficient, $S$ is the propellant burning surface area, $\rho_{S}$ is the propellant 
density and $A_{t}$ is the nozzle throat area.

When the Mach number of the flow over the propellant surface exceeds around 0.2 , in order to get better accuracy, the conservation equations of motion for the gas (and particles, if a two-phase mixture) within the flow can be employed, to better represent the flow's behavior. The burning rate at the given location on the propellant burning surface can also be established as a function of local flow conditions obtained from the conservation equations of motion. Because the gaseous combustion products produce a mass flux that moves in the propellant grain port along the axial direction from head-end to the nozzle, so for SRMs, the bulk-averaged core flow behavior along the propellant grain port can be modelled adequately in one dimension for combustors having larger L/D (length-to-diameter) ratios [13].

The QSROC simulation program in this study uses quasi-steady one-dimensional ordinary differential equations to estimate flow behavior. These equations are based on the conservation principles of mass, linear momentum and energy of the core flow in going from the head-end to the exhaust nozzle at a given time and location [6]; there is a set of ordinary differential equations in terms of $\Delta x$ for the two-phase flow (gas and particle). Here, $\Delta x$ is an element length from station 1 to the adjacent downstream station 2 (moving from the head end towards the exhaust nozzle). According to the conservation of mass relation for the gas, the following equation can be utilized:

$$
\begin{aligned}
\rho_{2} u_{2} A_{2} & =\rho_{1} u_{1} A_{1}+\overline{r_{b} \Delta S}\left[\left(1-\alpha_{p}\right) \rho_{s}-\rho\right] \\
& =B_{1}
\end{aligned}
$$

Here, $\Delta S$ is the segment peripheral surface area ( $\pi d \cdot \Delta x$ for the case of cylindrical-grain HREs). The overbar symbol stands for a mean value between the two stations. For the particles:

$$
\begin{aligned}
\rho_{p 2} u_{p 2} A_{2} & =\rho_{p 1} u_{p 1} A_{1}+\overline{r_{b} \Delta S}\left[\alpha_{p} \rho_{s}-\bar{\rho}_{p}\right] \\
& =B_{1 p}
\end{aligned}
$$

From the conservation of linear momentum for the gas: 


$$
\begin{aligned}
\rho_{2} u_{2}^{2} A_{2}= & \rho_{1} u_{1}^{2} A_{1}+p_{1}\left(\frac{A_{1}+A_{2}}{2}\right)+\overline{\Delta S}\left[\left(1-\alpha_{p}\right) \rho_{s} \overline{r_{b} u_{i}}-\overline{r_{b} \rho_{u}}-\frac{\overline{\rho u^{2} f}}{8}\right] \\
& -\left(\frac{A_{1}+A_{2}}{2}\right)\left[\frac{\overline{\rho_{p}}}{m_{p}} \bar{D}-\overline{\rho_{p}} a_{\ell}\right] \Delta x \\
& =B_{2}
\end{aligned}
$$

From the conservation of linear momentum for the particle phase:

$$
\begin{aligned}
\rho_{p 2} u_{p 2}^{2} A_{2} & =\rho_{p 1} u_{p 1}^{2} A_{1}+\alpha_{p} \rho_{s} \overline{r_{b} u_{i} \Delta S}-\overline{r_{b} \rho_{u} \Delta S}+\left(\frac{A_{1}+A_{2}}{2}\right)\left[\frac{\overline{\rho_{p}}}{m_{p}} \bar{D}-\overline{\rho_{p}} a_{\ell}\right] \Delta x \\
& =B_{2 p}
\end{aligned}
$$

From the conservation of energy for the gas:

$$
\begin{aligned}
\rho_{2} u_{2} A_{2}\left(C_{p} T_{2}+\frac{u_{2}^{2}}{2}\right) & =\rho_{1} u_{1} A_{1}\left(C_{p} T_{1}+\frac{u_{1}^{2}}{2}\right)+ \\
& \overline{\Delta S}\left[\overline{r_{b}} \rho_{s}\left(1-\alpha_{p}\right)\left(C_{p} T_{F}+\frac{\overline{v_{w}^{2}}}{2}\right)-h_{c}\left(\bar{T}-T_{w}\right)-\overline{r_{b} \rho}\left(C_{v} \bar{T}+\frac{\overline{u^{2}}}{2}\right)\right] \\
& -\left(\frac{A_{1}+A_{2}}{2}\right) \frac{\rho_{p}}{m_{p}}\left(\overline{u_{p} D}+\bar{Q}\right) \Delta x-\left(\frac{A_{1}+A_{2}}{2}\right) \overline{\rho u} a_{\ell} \Delta x \\
& =B_{3}
\end{aligned}
$$

From the conservation of energy for the particle phase:

$$
\begin{aligned}
\rho_{p 2} u_{p 2} A_{2}\left(C_{m} T_{p 2}+\frac{u_{p 2}^{2}}{2}\right) & =\rho_{p 1} u_{p 1} A_{1}\left(C_{m} T_{p 1}+\frac{u_{p 1}^{2}}{2}\right)+ \\
& {\left[\overline{r_{b}} \alpha_{p} \rho_{s}\left(C_{m} T_{F}+\frac{\overline{v_{w}^{2}}}{2}\right)-\overline{r_{b} \rho_{p}}\left(C_{m} \overline{T_{p}}+\frac{\overline{u_{p}^{2}}}{2}\right)\right] } \\
& +\left(\frac{A_{1}+A_{2}}{2}\right) \overline{\rho_{p}}\left(\overline{m_{p} D}+\bar{Q}\right) \Delta x-\left(\frac{A_{1}+A_{2}}{2}\right) \overline{\rho_{p} u_{p}} a_{\ell} \Delta x \\
& =B_{3 p}
\end{aligned}
$$

Accompanying the six equations, the equation of state for the gas is also needed to complete this set of equations: 


$$
p_{2}=\rho_{2} R T_{2}
$$

So, in this set of equations, there are seven unknown variables: $\rho_{2}, u_{2}, p_{2}, T_{2}, \rho_{p 2}, u_{p 2}, T_{p 2}$. In order to solve all these unknown variables, for convenience, one can first set:

$$
\lambda=\frac{2 A_{2}}{A_{1}+A_{2}}
$$

Then, by variable substitutions and algebraic manipulation, the axial velocity of gas at station 2 can be estimated via:

$$
u_{2}=\frac{-\frac{C_{p} B_{2} \lambda}{R} \pm \sqrt{\left(\frac{C_{p} B_{2} \lambda}{R}\right)^{2}+4\left(\frac{B_{1}}{2}-\frac{C_{p} B_{1} \lambda}{R}\right) B_{3}}}{2\left(\frac{B_{1}}{2}-\frac{C_{p} B_{1} \lambda}{R}\right)}
$$

It should be noted that there are two possible solutions for Eq. (22); one solution should be supersonic, another one, the more typical one, should be subsonic. Once one has the axial velocity at station 2 , the other unknown gas flow variables can be solved:

$$
\begin{gathered}
\rho_{2}=\frac{B_{1}}{A_{2} u_{2}} \\
p_{2}=\frac{2\left(B_{2}-B_{1} u_{2}\right)}{A_{1}+A_{2}} \\
T_{2}=\frac{\lambda u_{2}\left(B_{2}-B_{1} u_{2}\right)}{R B_{1}}=\frac{p_{2}}{R \rho_{2}}
\end{gathered}
$$

For the unknown particle phase variables:

$$
\begin{gathered}
\rho_{p 2}=\frac{B_{1 p}}{A_{2} u_{p 2}} \\
u_{p 2}=\frac{B_{2 p}}{B_{1 p}}
\end{gathered}
$$




$$
T_{p 2}=\frac{B_{3 p}}{B_{1 p} C_{m}}-\frac{u_{p 2}^{2}}{2 C_{m}}
$$

There is another more general approach for estimating the steady and unsteady flow conditions in SRMs that uses a set of partial differential equations based on the conservation equations of mass, linear momentum and energy for the gas and the particle. Because this general approach is not applied in the simulation programs being used here, further discussion on this topic will be put aside. The details about employing the set of partial differential equations can be found in Section 10.7 of [6], if the reader is interested.

\subsection{Combustion in Hybrid Rocket Engines}

The Figure 6 shows a diagram of the hybrid rocket engine burning process. The solid fuel first melts into a liquid, then vaporizes into a gas [14]. The gaseous fuel first enters the fuel vapor zone at the bottom of the boundary layer, and then fuel and oxidizer coming from the core flow mix and combust at the combustion front, or the active combustion zone in the middle of the boundary layer. Top of the boundary layer is the location for the resulting combustion reaction products. The combustion zone convects heat back to the fuel below, which is then melted and vaporized as it moves into the combustion zone.

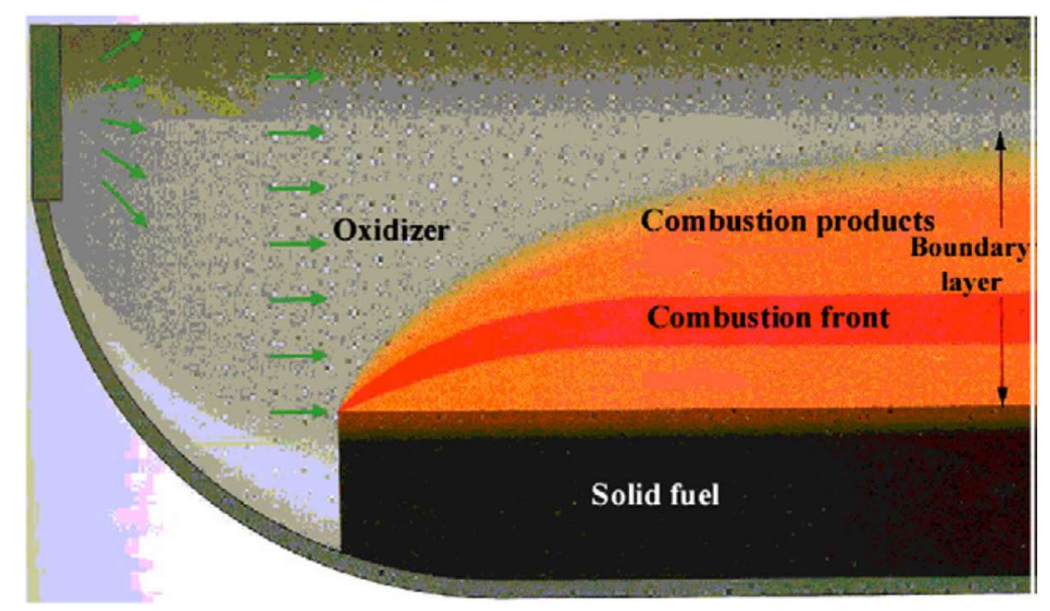

Figure 6 Diagram Illustrating Hybrid Rocket Engine Burning [15]

Different from the SRMs' propellant burning rate, an HRE's fuel surface regression rate is typically 
a function of local axial mass flux (and not dependent on pressure). Fuel surface regression rate can be estimated via the following simple empirical formula:

$$
r_{b}=a G^{n}, \quad 0.4<n<0.85
$$

where $a$ and $n$ are experimentally determined coefficients. Over the years, there are other proposed approaches to model the fuel regression rate to consider, such as the Sutton-Biblarz model [7]:

$$
r_{b}=0.036 \frac{G^{0.8}}{\rho_{s}}\left(\frac{\mu}{x}\right)^{0.2} \beta_{1}^{0.23}
$$

where $x$ is the axial location along the fuel grain inner port, $\mu$ is the combustion gas viscosity, $\beta_{1}$ is a non-dimensional fuel mass flux reflecting fuel vaporization evaluated at the fuel grain surface, as provided in [16]. Similar to the L-R model for SRMs, these models lack universality. For prediction purposes, a more universal model is needed.

It has been observed that the dominant fuel regression mechanism in HREs is via convective heat transfer, which is mainly based on axial mass flux, correlating to the previously discussed erosive burning mechanism for SRMs [6]. So, the Greatrix-Gottilieb [8] erosive burning model can be applied to HREs. The overall regression rate can be estimated via:

$$
r_{b}=\frac{h\left(T_{F}-T_{S}\right)}{\rho_{s}\left[C_{s}\left(T_{S}-T_{i}\right)-\Delta H_{s}\right]}+r_{o}
$$

Here, $r_{o}$ is the base fuel surface regression rate that is caused by all other mechanisms such as spin and acceleration, etc. Because there is no spin, acceleration and any other elements that can add a component to the overall burning rate in the simulations of the present study, the base fuel surface regression rate $r_{O}$ is not significant, and can be ignored. The overall regression rate, as a result, can be estimated via a logarithmic relation that arises from a thin-film-theory treatment of the transpiration effect on the convective heat transfer to the burning fuel surface: 


$$
r_{b}=\frac{h^{*}}{\rho_{s} C_{p}} \ln \left[1+\frac{C_{p}}{C_{s}} \frac{\left(T_{F}-T_{S}\right)}{\left(T_{S}-T_{i}-\Delta H_{s} / C_{s}\right)}\right]
$$

Using Eq. (32), combining with the set of equations (Eq. (5) and (6)) previously discussed in the SRM erosive burning model, the HRE fuel surface regression rate model has been produced. In order to better estimate for total heat transfer effect, the net surface heat of reaction $\Delta H_{s}$ can be counted, if the value is significant. But, according to past studies, the contribution of the net surface heat of reaction to the overall burning rate is usually ignored, so in the present study, this value will be set to zero. The prediction of internal ballistic behavior based on this model has to date agreed well with actual firing data [1].

When the Mach number of the flow over the solid fuel grain surface is lower than a moderate subsonic level, the chamber pressure can be estimated via:

$$
p_{c}=\left[\frac{\gamma}{R T_{f}}\left(\frac{2}{\gamma+1}\right)^{\frac{\gamma+1}{\gamma-1}}\right]^{0.5} \cdot \frac{\rho_{s} S a\left(\frac{\dot{m}_{O}}{A_{P}}\right)^{n}+\dot{m}_{O}}{A_{t}}
$$

When the Mach number of flow in the solid fuel grain port exceeds the low subsonic limit, the conservation relations for the motion of the gas and particles within the flow can also be employed. As noted earlier for solid rocket motor, the mass flux in the propellant grain port moves along the axial direction from head-end towards the nozzle, such that the core flow behavior along the fuel grain port can be modelled adequately in one axial dimension if a longer L/D geometry for effective flow channel.

Similar to the QSROC simulation program, the QSHYB internal ballistic simulation program in this study uses quasi-steady one-dimensional ordinary differential equations to estimate mass, linear momentum and energy of the combustor's core gas, in this case going from the head-end injector to the exhaust nozzle at a given time and location:

$$
\frac{d(\rho u)}{d x}=-\frac{1}{A} \frac{d A}{d x} \rho u+\left(1-\alpha_{p}\right) \rho_{s} \frac{4 r_{b}}{d}-\left(\frac{4 r_{b}}{d}\right) \rho
$$




$$
\begin{gathered}
\frac{d}{d x}\left(\rho u^{2}+p\right)=-\frac{1}{A} \frac{d A}{d x} \rho u^{2}-\left(\frac{4 r_{b}}{d}\right) \rho u-\rho a_{\ell}-\frac{\rho_{p}}{m_{p}} D \\
\frac{d}{d x}(\rho u E+u p)=-\frac{1}{A} \frac{d A}{d x}(\rho u E+u p)-\left(\frac{4 r_{b}}{d}\right) \rho E \\
+\left(1-\alpha_{p}\right) \rho_{s} \frac{4 r_{b}}{d}\left(C_{p} T_{f}+\frac{v_{f}^{2}}{2}\right)-\rho u a_{\ell}-\frac{\rho_{p}}{m_{p}}\left(u_{p} D+Q\right)
\end{gathered}
$$

Here, the gas can be considered as ideal so the total specific energy of gas $E$ can be calculated via:

$$
E=\frac{p}{[(\gamma-1) \rho]}+\frac{u^{2}}{2}
$$

Similar to the case of SRMs, the mass, linear momentum and energy of the monodisperse inert (nonburning) particle phase in the core flow can be estimated a set of quasi-steady one-dimensional ordinary differential equations:

$$
\begin{gathered}
\frac{d\left(\rho_{p} u_{p}\right)}{d x}=-\frac{1}{A} \frac{d A}{d x} \rho_{p} u_{p}+\alpha_{p} \rho_{s} \frac{4 r_{b}}{d}-\left(\frac{4 r_{b}}{d}\right) \rho_{p} \\
\frac{d\left(\rho_{p} u_{p}^{2}\right)}{d x}=-\frac{1}{A} \frac{d A}{d x} \rho_{p} u_{p}^{2}-\left(\frac{4 r_{b}}{d}\right) \rho_{p} u_{p}-\rho_{p} a_{\ell}+\frac{\rho_{p}}{m_{p}} D \\
\frac{d}{d x}\left(\rho_{p} u_{p} E_{p}\right)=-\frac{1}{A} \frac{d A}{d x}\left(\rho_{p} u_{p} E_{p}\right)-\left(\frac{4 r_{b}}{d}\right) \rho_{p} E_{p} \\
+\alpha_{p} \rho_{s} \frac{4 r_{b}}{d}\left(C_{m} T_{f}+\frac{v_{f}^{2}}{2}\right)-\rho_{p} u_{p} a_{\ell}+\frac{\rho_{p}}{m_{p}}\left(u_{p} D+Q\right)
\end{gathered}
$$

For the grain location that is downstream from the stoichiometric length position, there is no combustion, because there is no oxidizer remaining. But, with the core flow temperature still hot, the fuel grain still ablates or regresses, albeit likely at a lower rate. The regression rate of this ablation phenomenon can also be estimated via:

$$
e_{s}=\frac{h^{*}}{\rho_{s} C_{p}} \ln \left[1+\frac{C_{p}}{C_{s}} \frac{\left(T_{\infty}-T_{d s}\right)}{\left(T_{d s}-T_{i}-\Delta H_{s} / C_{s}\right)}\right]
$$


Here, $T_{\infty}$ is the core flow temperature, and $T_{d s}$ is the effective decomposition gas temperature. Because of the absence of combustion, the $\Delta H_{S}$ value will likely be small.

\subsection{Internal Ballistic Performance Parameters}

The internal ballistic performance parameters that are analyzed and compared in the present study include chamber pressure, thrust, total impulse and specific impulse. For hybrid rocket engines, the stoichiometric length is also needed to be considered.

The thrust produced by a rocket motor/engine nozzle can be estimated via:

$$
F=\dot{m}_{e} u_{e}+\left(p_{e}-p_{\infty}\right) A_{e}
$$

Here, $\dot{m}_{e}$ is the mass flow at the nozzle exit. Because the flow in the nozzle is assumed to be isentropic, and there is no mass injection at the divergent part of nozzle, the choked mass flow at the throat can be estimated via:

$$
\dot{m}_{e}=\dot{m}_{t}=\left[\frac{\gamma}{R T_{F}}\left(\frac{2}{\gamma+1}\right)^{\frac{\gamma+1}{\gamma-1}}\right]^{\frac{1}{2}} A_{t} p_{c}
$$

The flow velocity at nozzle exit can be estimated via:

$$
u_{e}=a_{e} \cdot M a_{e}=\left[R T_{F}\left(\frac{2 \gamma}{\gamma-1}\right)\left\{1-\left(\frac{p_{e}}{p_{c}}\right)^{\frac{\gamma-1}{\gamma}}\right\}\right]^{\frac{1}{2}}
$$

Substituting Eqs. (43) and (44) into Eq. (42), the thrust can be calculated via:

$$
F=C_{F} A_{t} p_{c}=C_{F, v}\left[1-\left(\frac{p_{e}}{p_{c}}\right)^{\frac{\gamma-1}{\gamma}}\right]^{\frac{1}{2}} A_{t} p_{c}+\left(p_{e}-p_{\infty}\right) A_{e}
$$

Here, the vacuum thrust coefficient $C_{F, v}$ can be calculated via: 


$$
C_{F, v}=\left[\frac{2 \gamma^{2}}{\gamma-1}\left(\frac{2}{\gamma+1}\right)^{\frac{\gamma+1}{\gamma-1}}\right]^{\frac{1}{2}}
$$

Because the flow in the nozzle is isentropic and choked, the Mach number of flow at the nozzle throat $M a_{t}$ is 1. Based on this, the nozzle exit Mach number $M a_{e}$ can be calculated via:

$$
\frac{A_{t}}{A_{e}}=\frac{M a_{e}}{M a_{t}}\left[\frac{2+(\gamma-1) M a_{t}^{2}}{2+(\gamma-1) M a_{e}^{2}}\right]^{\frac{\gamma+1}{2(\gamma-1)}}=M a_{e}\left[\frac{\gamma+1}{2+(\gamma-1) M a_{e}^{2}}\right]^{\frac{\gamma+1}{2(\gamma-1)}}
$$

After getting the Mach number of flow at the nozzle exit, the nozzle exit pressure $p_{e}$ can also be calculated via:

$$
p_{e}=p_{c}\left[1+\frac{\gamma-1}{2} M a_{e}^{2}\right]^{\frac{-\gamma}{\gamma-1}}
$$

Estimating chamber pressure and thrust is not sufficiently general for the overall performance analysis of a propulsion system. Engineers always want propulsion systems with higher efficiency, if possible. Higher efficiency means that the propulsion system can use less fuel, or the vehicle can take more payload in the same flight mission. There is a simple parameter that can help to make a judgment as to the efficiency of a propulsion system, and that is specific impulse. The specific impulse $I_{s p}$ is defined by:

$$
I_{s p}=\frac{F}{\dot{m} g_{o}}
$$

Here, $F$ is the thrust of the propulsion system, $g_{o}$ is the reference (sea-level) gravity acceleration and $\dot{m}$, for rocket motors or engines, is the mass flow at the nozzle throat. This parameter can be calculated by:

$$
\dot{m}_{t}=\dot{m}_{e}=\frac{1}{c^{*}} A_{t} p_{c}
$$

The $c^{*}$ here is called the characteristic exhaust velocity which can be determined by: 


$$
c^{*}=\left[\frac{\gamma}{R T_{F}}\left(\frac{2}{\gamma+1}\right)^{\frac{\gamma+1}{\gamma-1}}\right]^{-\left(\frac{1}{2}\right)}
$$

But the specific impulse obtained from this equation is the instantaneous value. The average specific $\bar{I}_{s p}$ impulse for a firing can be estimated via:

$$
\bar{I}_{s p}=\frac{1}{g_{o} m_{p}} I_{t o t}
$$

Here, $m_{p}$ is the propellant mass and the $I_{\text {tot }}$ is the total impulse. The total impulse is also important for a propulsion system; it can be estimated via:

$$
I_{t o t}=\int_{0}^{t_{b}} F d t
$$

Here, $t_{b}$ is the burning time of the engine.

For the hybrid rocket engine, the stoichiometric length is also a parameter that is necessary for observing the overall performance. This parameter is used to help estimate the efficiency of an HRE. When the stoichiometric length is higher than $100 \%$, there is unreacted oxidizer leaving the combustor chamber and entering the nozzle. The cooler unreacted oxidizer, if of significant quantity, can produce a lower overall flame temperature in the combustion chamber. When the stoichiometric length is lower than $100 \%$, there is unreacted solid fuel ablating from the fuel grain, entering into the central port flow and then entering the nozzle. The ablation process effectively removes heat from the upstream gas flow, so that the flame temperature is also lower than the standard value. The HRE is working at lower efficiency under both situations, i.e., when being significantly below or above the $100 \%$ value for the stoichiometric length. The stoichiometric length should be as close to $100 \%$ as is practically possible (sometimes, during some parts of an HRE firing, e.g., early on or much later into an engine firing, it is not practical), in order to have the engine work at the best level of efficiency.

Actually, the oxidizer-fuel ratio in the combustion chamber of an HRE is not a fixed value because 
it changes with the progression of the firing in time. Picking up a position on the axial direction of the solid fuel grain, the oxidizer-fuel ratio at this position can be modeled as a function of the distance from this position to the head-end $x$ and the burn time $t$. When oxidizer mass flow rate is a constant value, the $r(x, t)$ always goes up as the firing progresses. When designing an HRE, the solid fuel grain length is set to coincide with the stoichiometric oxidizer-fuel ratio at some point during the engine's firing. Based on the empirical law for mass-flux dependent burning (Eq. (29)), the stoichiometric length can be estimated via:

$$
L_{s t} \approx \frac{G_{O} d}{4 \rho_{s} r_{s t} r_{b}} \approx \frac{G_{O}^{1-n} d}{4 a \rho_{s} r_{s t}} \approx f\left(d^{2 n-1}\right)
$$

where

$$
r_{s t}=\frac{\dot{m}_{o}}{\dot{m}_{f}} \mid \text { stoich } \approx \frac{G_{O} A_{p}}{\rho_{s} r_{b} \cdot \pi d L_{s t}}
$$

As mentioned in Section 2.2, the coefficient $a$ changes with the various HRE configurations and it also tends to decrease during the firing, with the grain inner port diameter increasing [6]. So, an alternative expression is developed [1], based on the Greatrix fuel surface regression rate model:

$$
L_{s t} \approx \frac{G_{O} d}{4 \rho_{s} r_{s t} r_{b}} \approx \frac{2 \operatorname{Pr}^{\frac{2}{3}} d}{f \cdot[\ln (\beta)]\left(r_{s t}\right)}
$$

where

$$
\beta=1+\frac{C_{p}}{C_{s}} \frac{\left(T_{F}-T_{s}\right)}{\left(T_{s}-T_{i}-\Delta H_{s} / C_{s}\right)}
$$

In the QSHYB simulation program for this study, when stoichiometric length is larger than the fuel grain length, the following equations are applied:

$$
\Delta l_{f}=\frac{\dot{m}_{o}-r_{s t} \cdot \sum_{i=1}^{N} \rho_{s} r_{b} \Delta S}{r_{s t} \rho_{s} r_{b_{N}} \pi d_{p_{N}}}
$$




$$
l_{s t}=\frac{l_{f}+\Delta l_{f}}{l_{f}} \cdot 100 \%
$$

Here, the incremental peripheral burning surface area $\Delta S$ is a function of the node-dependent axial element length $\Delta x$, which is also node-dependent. The parameter $N$ is the total number of nodes (elements) along the axial length of the fuel grain, hence the $N^{t h}$ position is the node at the fuel grain port exit. For some stoichiometric length-time profiles displayed in this study, there are some small but noticeable discontinuous "steps" on those curves that are caused by the lower number of nodes being employed. Although these "steps" can be avoided by setting a larger number of elements, there would be no significant influence on the accuracy of critical parameters like chamber pressure and thrust, and at the same time, the simulation calculation time will be longer. In the present study, the number of nodes for all of the HRE simulation firings are set to 100 for the fuel (or propellant) grain, which, based on past studies, is demonstrably large enough to provide the needed accuracy for the internal ballistic behavior analysis being done in this study. 


\section{Simulation Parameters}

Table 1 shows the characteristics for three example existing solid rocket motors that form the reference baseline for this study. The cylindrical-grain motor is described by Jackson et al [17], the wagon-wheel-grain motor coming from the second stage of the dual-interrupted-thrust pulse motor (DIT $2^{\text {nd }}$ stage) described by Carrier et al. [18], and both of these two motors utilize an aluminized ammonium perchlorate and hydroxyl-terminated polybutadiene (AP/HTPB) propellant. The star-grain motor is the NOTS 551-B discussed by Lucy [19], and this motor utilizes an aluminized AP/PU (polyurethane) composite propellant. All of the three motors are simulated under static conditions at sea level, without any spin, swirl or axial acceleration.

Table 1 Solid Rocket Motor Characteristics

\begin{tabular}{|c|c|c|c|}
\hline Motor & Cylindrical-Grain & Star-Grain & Wagon-Wheel-Grain \\
\hline Propellant grain length (m) & 0.835 & 2.25 & 1.835 \\
\hline Chamber wall diameter $(\mathrm{cm})$ & 12.7 & 34 & 19.844 \\
\hline Inner casing diameter $(\mathrm{cm})$ & 6.35 & 6.5 & 4.58 \\
\hline Nozzle throat diameter (cm) & 2.03 & 5.5 & 4.06 \\
\hline Pressure-based burn rate exponent & 0.25 & 0 & 0.25 \\
\hline Pressure-based burn rate coefficient $\left(\mathrm{cm} / \mathrm{s} / \mathrm{kPa}^{\mathrm{n}}\right)$ & 0.0664 & 0.3 & 0.0664 \\
\hline Propellant density $\left(\mathrm{kg} / \mathrm{m}^{3}\right)$ & 1740 & 1700 & 1740 \\
\hline Propellant specific heat $(\mathrm{J} / \mathrm{kg} \cdot \mathrm{K})$ & 1540 & 1300 & 1540 \\
\hline Flame temperature $(\mathrm{K})$ & 3060 & 2400 & 3060 \\
\hline Propellant burning surface temperature (K) & 1130 & 665 & 1130 \\
\hline Initial propellant surface temperature (K) & & 294 & \\
\hline Gas specific heat $(\mathrm{J} / \mathrm{kg} \cdot \mathrm{K})$ & 1845 & 1975 & 1845 \\
\hline Gas molecular weight (amu) & 26.1 & 21 & 26.1 \\
\hline
\end{tabular}

The cross sections of grains used for the example comparator HREs are the same as the cross sections of grains used for the reference SRMs. All of the three example HREs utilize hydroxylterminated polybutadiene (HTPB) as the solid fuel and nitrous oxide $\left(\mathrm{N}_{2} \mathrm{O}\right)$ as the liquid oxidizer (the 
stoichiometric mixture ratio of this propellant combination is 6.5). The oxidizer enters the combustion chamber through the head-end injector, and the oxidizer mass flow (OMF, $\left.\dot{m}_{o}\right)$ rate of the three engines are also set to the same value. The same fuel-oxidizer combination means that some characteristics are shared among the three hybrid engines. For HREs, the temperature of the oxidizer at the head-end injector location is usually set a bit lower than the flame temperature. Based on experimental firing experience, the difference is usually set to $50 \mathrm{~K}$. The oxidizer mass flow of the three engines is fixed during the combustion (firing) process. Due to the axial mass flux dependence characteristic of HREs, the internal ballistic performance of the three HREs under different oxidizer mass flows can also be simulated, in order to illustrate the influence of different oxidizer mass flow values on these three grain designs. The total oxidizer mass for each simulation is $16.4 \mathrm{~kg}$. Similarly, for the SRMs, the three HREs are simulated under static conditions at sea level, without any spin, swirl and axial acceleration. Table 2 shows the characteristics for the three example hybrid rocket engines.

Table 2 Hybrid Rocket Engine Characteristics

\begin{tabular}{|c|c|c|c|}
\hline Motor & Cylindrical-Grain & Star-Grain & Wagon-Wheel-Grain \\
\hline Propellant grain length $(\mathrm{m})$ & 0.48 & 0.25 & 0.24 \\
\hline Chamber wall diameter $(\mathrm{cm})$ & 12.7 & 34 & 19.844 \\
\hline Inner casing diameter $(\mathrm{cm})$ & 6.35 & 6.5 & 4.58 \\
\hline Nozzle throat diameter $(\mathrm{cm})$ & & 1.285 & \\
\hline Oxidizer mass flow (kg/s) & & 0.385 & \\
\hline Solid fuel density $\left(\mathrm{kg} / \mathrm{m}^{3}\right)$ & & 1400 & \\
\hline Solid fuel specific heat $(\mathrm{J} / \mathrm{kg} \cdot \mathrm{K})$ & & 2100 & \\
\hline Flame temperature $(\mathrm{K})$ & & 2800 & \\
\hline Solid fuel burning surface temperature (K) & & 800 & \\
\hline Oxidizer temperature at injector (K) & & 2750 & \\
\hline Initial propellant surface temperature (K) & & 294 & \\
\hline Gas specific heat $(\mathrm{J} / \mathrm{kg} \cdot \mathrm{K})$ & & 1920 & \\
\hline Gas molecular weight (amu) & & 26 & \\
\hline
\end{tabular}




\section{Simulation Results and Discussion}

In the present study, two Ryerson University internal ballistic simulation programs, QSROC and QSHYB, are used to respectively simulate the internal ballistic performance of solid rocket motors and hybrid rocket engines. Both of these programs for SRMs and HREs utilize the two respective propellant burning/fuel regression rate models that were discussed in Chapter 2.

\subsection{Cylindrical Grain}

To begin the present study, the internal ballistic behavior of a cylindrical-grain SRM is examined. Figures 7 and 8 show the progressive ramping-up pressure-time profile and thrust-time profile of the cylindrical-grain SRM as predicted by the QSROC simulation program. With the propellant grain burning outward (radially), the pressure and thrust keep increasing. When the chamber wall is reached, the chamber pressure and thrust drop until the final extinguishment of the propellant is completed. This latter process is called the "tail-off". For this cylindrical-grain SRM, the "tail-off" phase starts at around $4.55 \mathrm{~s}$ after the firing began. This time is also where the chamber pressure and thrust reach the highest value. The maximum value of chamber pressure is $18.65 \mathrm{MPa}$ and the maximum value of thrust at sea level is $9.01 \mathrm{kN}$. The total burning process lasts $5.25 \mathrm{~s}$. Note that the initial ignition and chamber-filling phase is not accounted for by the simulation program, hence the main firing phase is assumed to begin at $t=0 \mathrm{~s}$. Initial filling phase aside, the predicted pressure-time and thrust-time profiles agree well with the actual firing data. The total impulse $I_{\text {tot }}$ of this motor is $30703.1 \mathrm{~N} \cdot \mathrm{s}$, and the specific impulse $I_{s p}$ is $223.6 \mathrm{~s}$. 


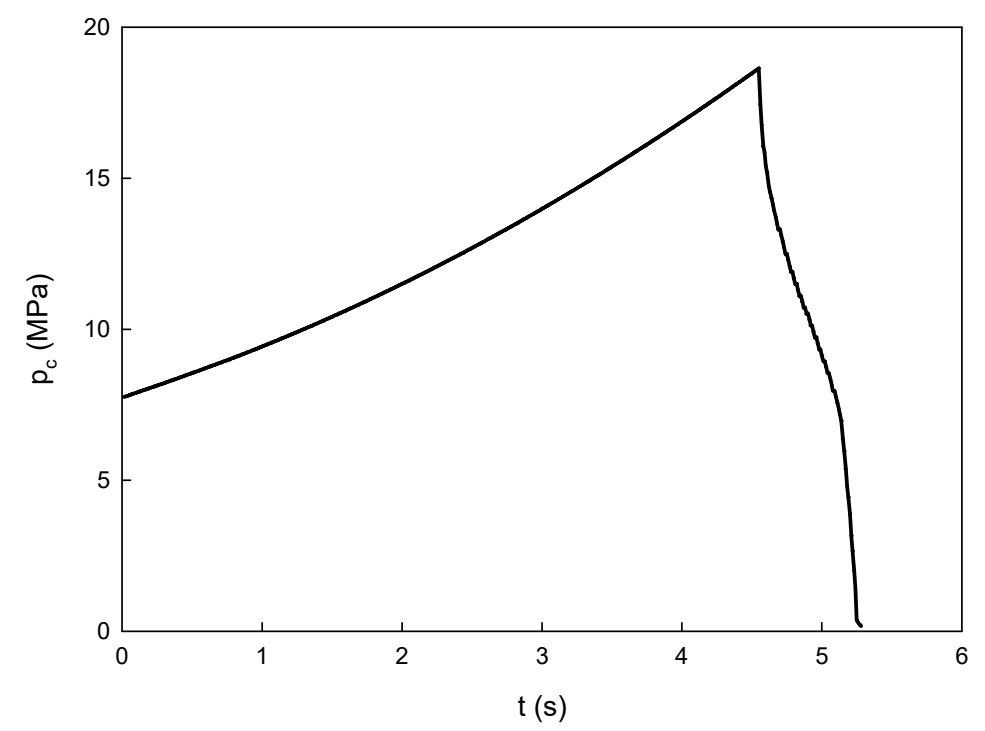

Figure 7 Predicted Pressure-Time Profile for Cylindrical-Grain SRM

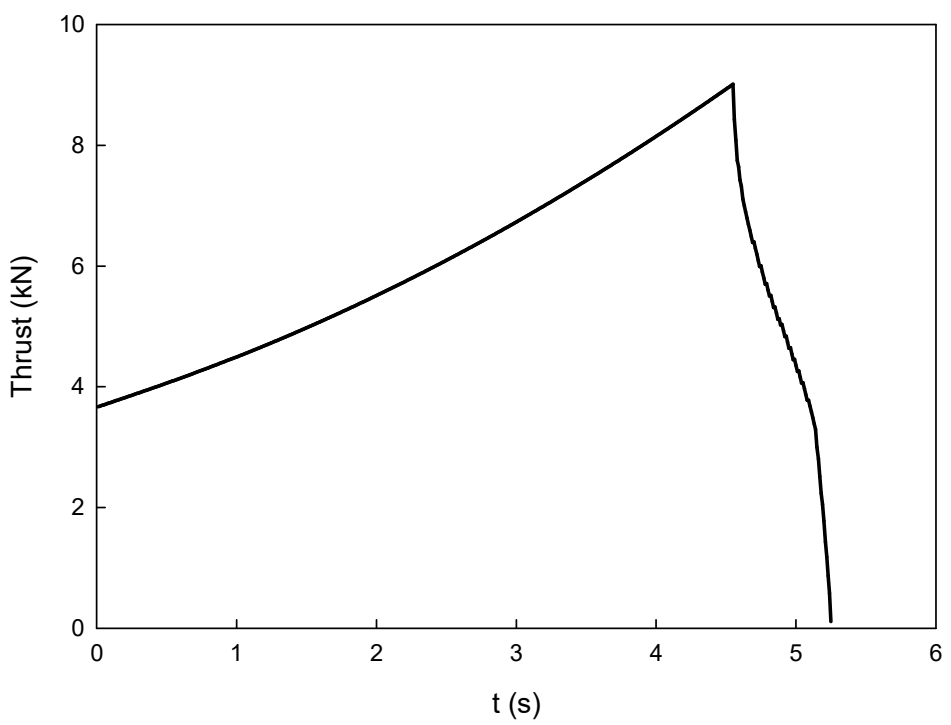

Figure 8 Predicted Thrust-Time Profile for Cylindrical-Grain SRM

When applying the same grain design for the comparator HRE, the internal ballistic behavior changes. Figures 9 and 10 show the pressure-time profile and thrust-time profile of the cylindricalgrain HRE as produced by the simulation program. Different from the progressive profile of the SRM, the profiles of the HRE are moderately regressive (mildly ramping down; close to being neutral, i.e., constant or "flat"). The maximum value of chamber pressure and thrust, $4.91 \mathrm{MPa}$ and $0.94 \mathrm{kN}$, appear at the beginning of the main firing phase, and then both of these parameters drop gradually 
to $4.7 \mathrm{MPa}$ and $0.89 \mathrm{kN}$ until the fuel grain completely burns out. The total impulse $I_{\text {tot }}$ of this engine is $39193.5 \mathrm{~N} \cdot \mathrm{s}$, and the specific impulse $I_{s p}$ is $230 \mathrm{~s}$.

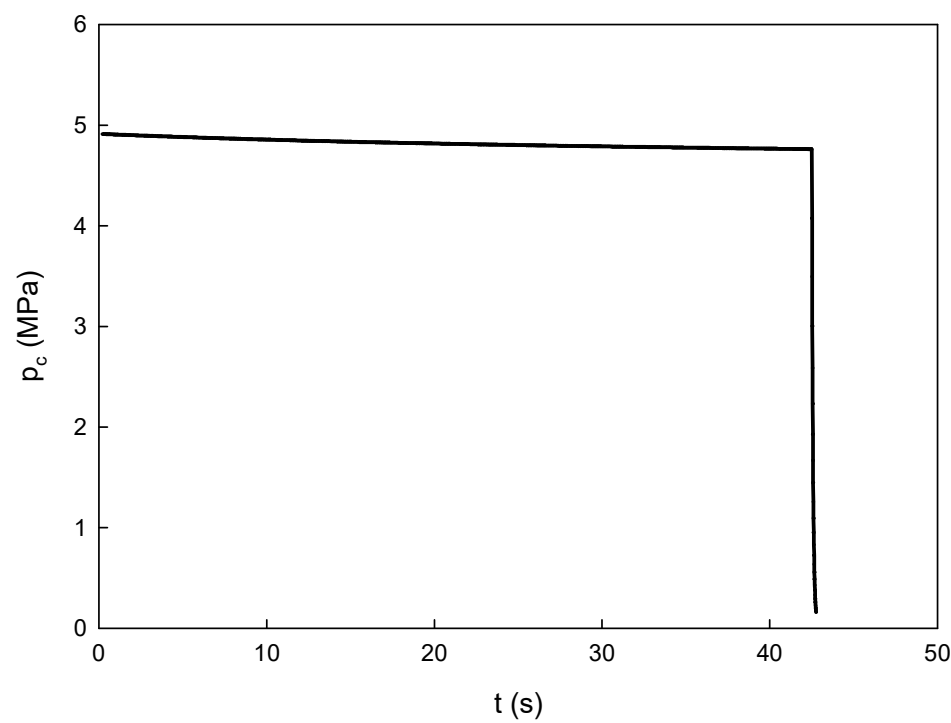

Figure 9 Predicted Pressure-Time Profile for Cylindrical-Grain HRE

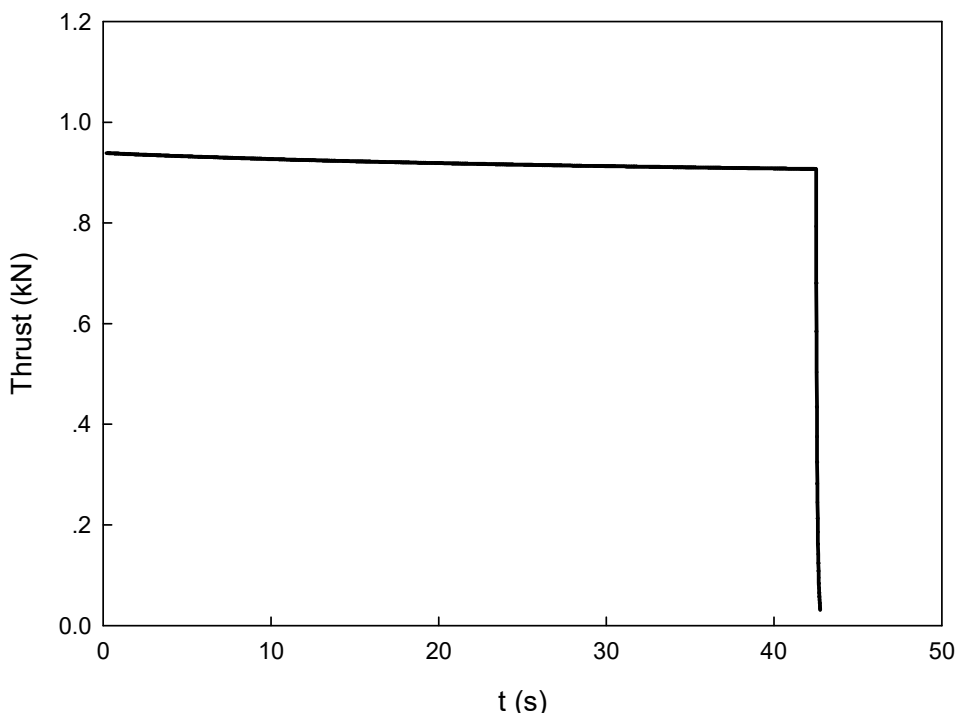

Figure 10 Predicted Thrust-Time Profile for Cylindrical-Grain HRE

As mentioned in Section 2.3, for the internal ballistic behavior of HREs, the stoichiometric length is another parameter that needs to be observed. The stoichiometric length is given in terms of percentage of the fuel grain length. Figure 11 shows the predicted stoichiometric length-time profile for the cylindrical-grain HRE. During the combustion process, the stoichiometric length increases from 
$110.4 \%$ to $146.3 \%$ which indicates that there is unreacted oxidizer entering the exhaust nozzle. According to the stoichiometric length-time profile shown in Figure 11, it is clear that with the progression in time of the engine's firing, the amount of the unreacted oxidizer entering the nozzle keeps increasing.

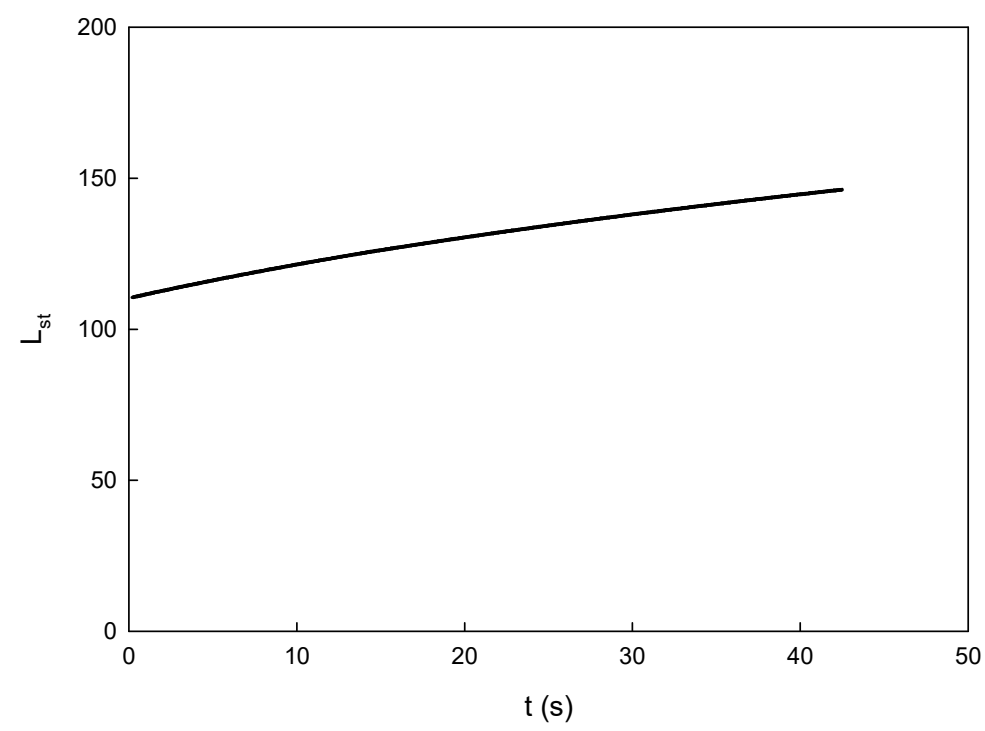

Figure 11 Predicted Stoichiometric Length-Time Profile for Cylindrical-Grain HRE

Based on the simulation results above, it is clear that the internal ballistic behavior for a comparable cylindrical-grain employed in the SRM and HRE is in fact quite different.

\subsection{Star Grain}

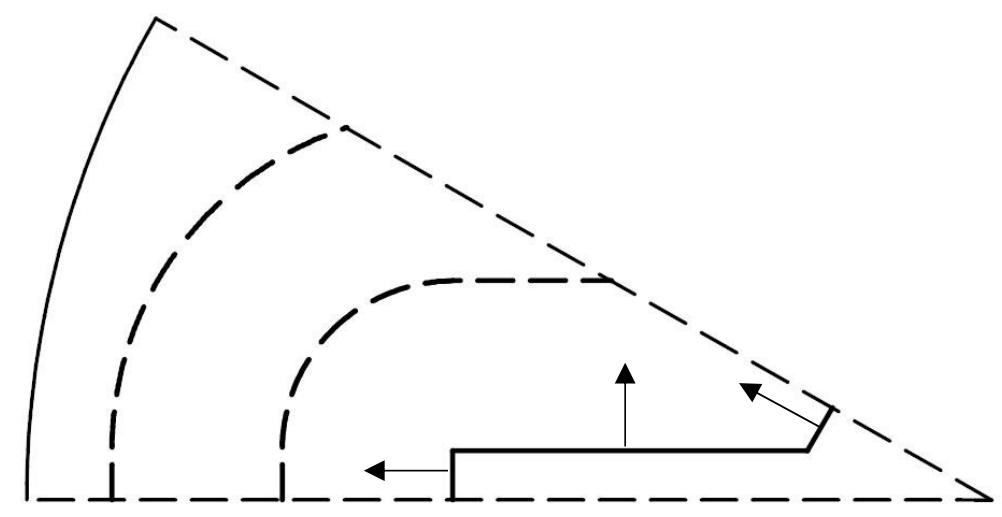

Figure 12 Star-Grain Cross Section Profile (30 Pie Section) with Burn Back 
Figure 12 shows the cross section (symmetric $30^{\circ}$ pie section) profile of the star-grain configuration used by the second reference SRM [19]. The diagram illustrates the changing grain profile with burn back. The cross section geometry changing during the firing process is analyzed in Appendix A.

Figure 13 and 14 show the pressure-time profile and sea-level thrust-time profile for the stargrain SRM. The maximum value of chamber pressure and thrust occur at the beginning of the firing main phase. During the first $10 \mathrm{~s}$, chamber pressure and thrust drop rapidly as the erosive burning contribution subsides. At around $10 \mathrm{~s}$, the internal combustion behavior profile transitions into a more neutral profile for much of the remaining main firing phase. The chamber pressure and thrust moderately increase until $24.7 \mathrm{~s}$ into the firing, then both parameters start to drop. The "tail-off" phase begins at around $34 \mathrm{~s}$. The entire firing process lasts $40 \mathrm{~s}$. The internal combustion behavior of this grain design can be described as "regressive-neutral". Initial filling phase aside, the predicted pressure-time and thrust-time profiles agree well with the actual firing data. The total impulse $I_{\text {tot }}$ of this motor is $659364.9 \mathrm{~N} \cdot \mathrm{s}$, and the specific impulse is $212 \mathrm{~s}$.

As a side note, this type of internal ballistic behavior can provide a rocket vehicle an "acceleration-cruise" flight mission profile in terms of forward speed of the vehicle.

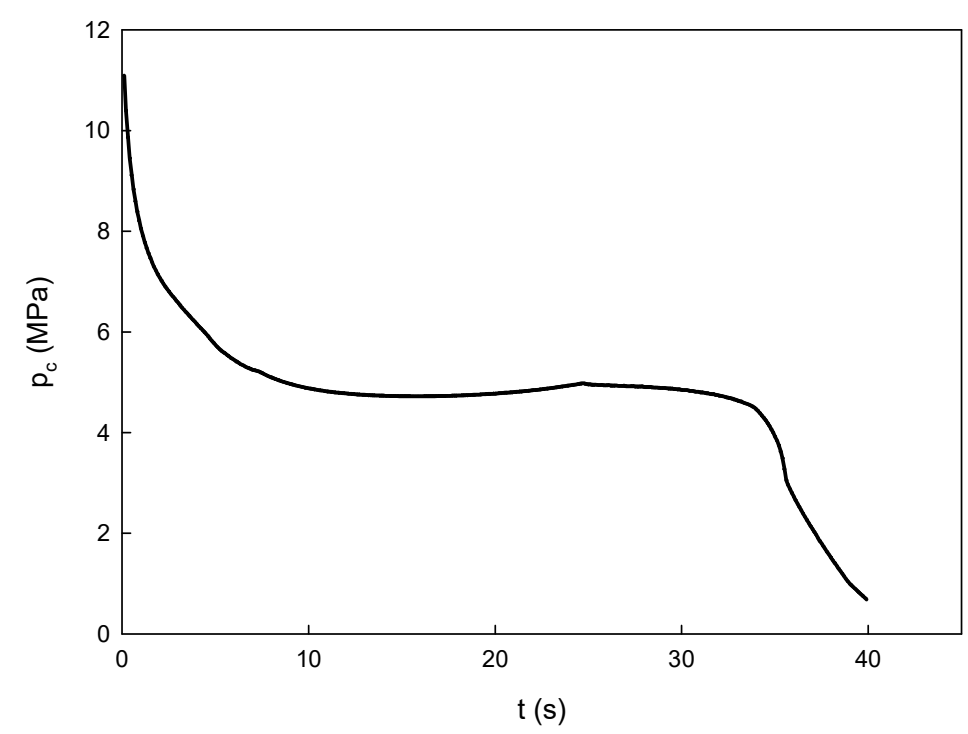

Figure 13 Predicted Pressure-Time Profile for Star-Grain SRM 


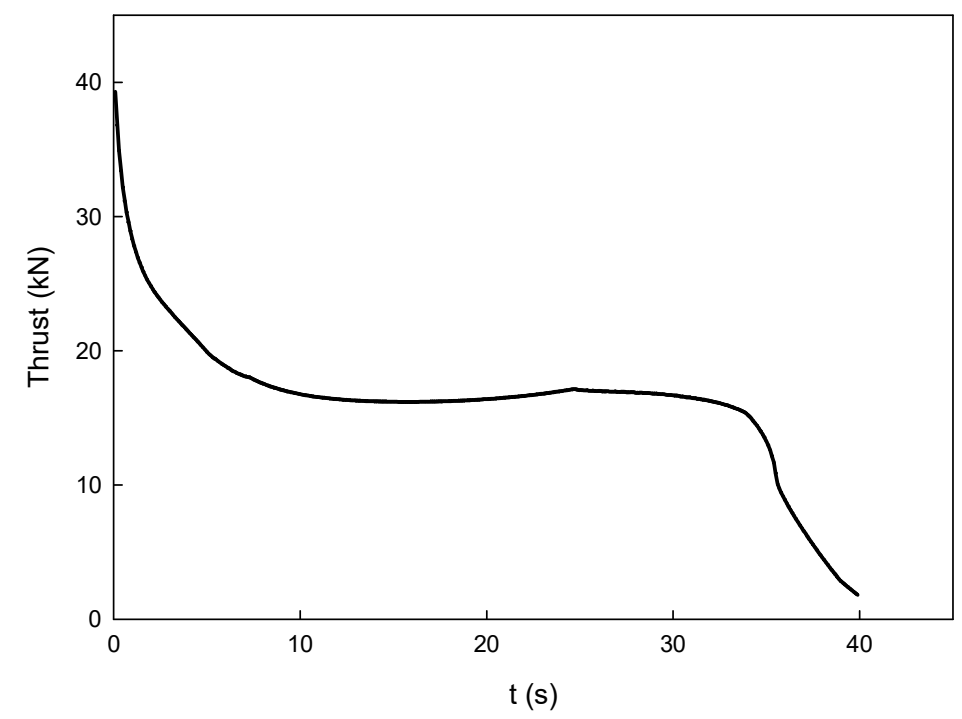

Figure 14 Predicted Thrust-Time Profile for Star-Grain SRM

Figures 15 and 16 show the pressure-time and thrust-time profile for the corresponding stargrain HRE. The chamber pressure and thrust drop slowly after the start of main firing phase, which is very similar to the case of the cylindrical-grain HRE. Chamber pressure drops from $4.99 \mathrm{MPa}$ to 4.77 MPa while thrust drops from $0.95 \mathrm{kN}$ to $0.91 \mathrm{kN}$. The total impulse $I_{\text {tot }}$ of this engine is $39466.6 \mathrm{~N} \cdot \mathrm{s}$, and the specific impulse $I_{s p}$ is $218.1 \mathrm{~s}$.

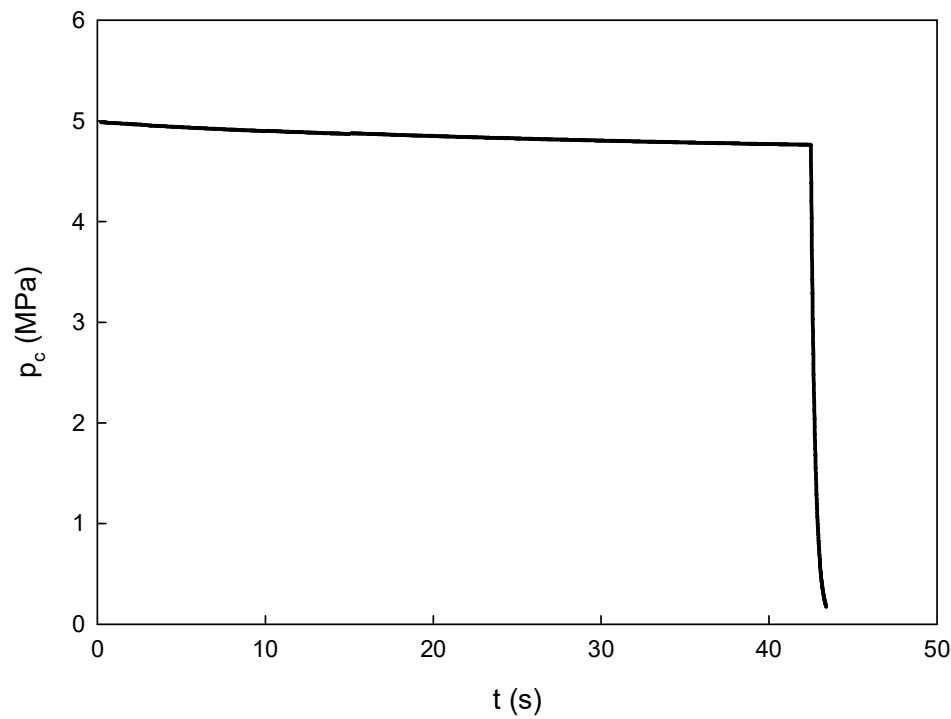

Figure 15 Predicted Pressure-Time Profile for Star-Grain HRE 


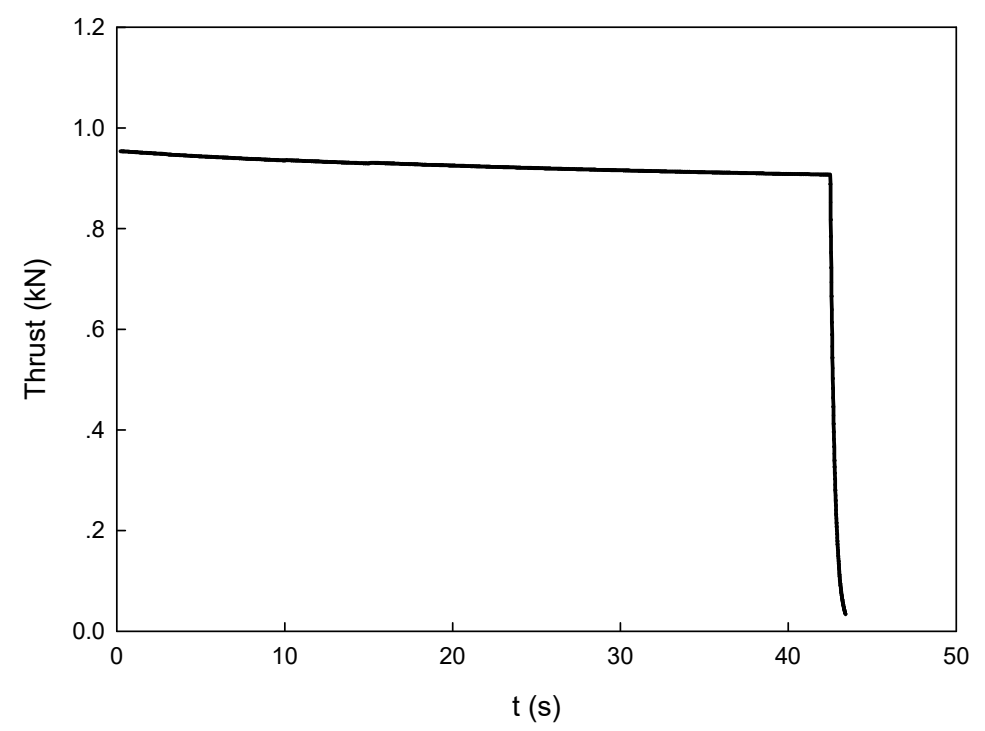

Figure 16 Predicted Thrust-Time Profile for Star-Grain HRE

The stoichiometric length-time profile for the star-grain HRE shown in Figure 17 is similar to the cylindrical-grain HRE. Stoichiometric length keeps increasing during the firing process. However the total change in $L_{s t}$ for the star-grain HRE is much larger than for the cylindrical-grain HRE. At the beginning of firing, the stoichiometric length is $93.7 \%$. When the firing ends, this value reaches $340.1 \%$. In this case, it is clearer than the case of the cylindrical-grain HRE that the growth rate of stoichiometric length decreases during the firing process.

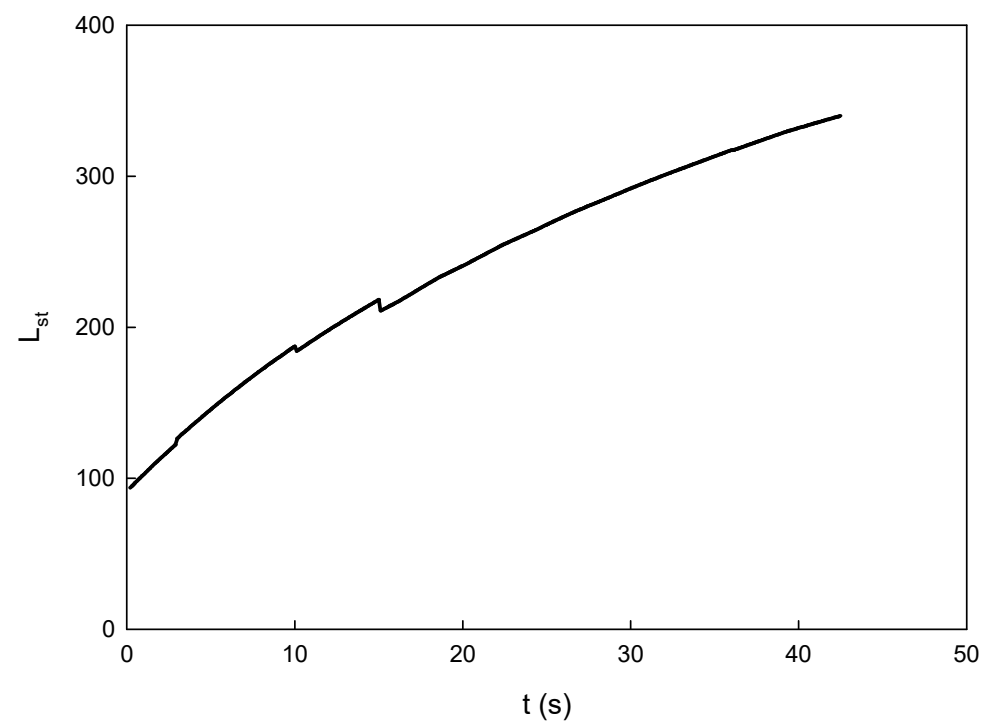

Figure 17 Predicted Stoichiometric Length-Time Profile for Star-Grain HRE 
Similar to the cylindrical-grain case, the star-grain performs differently when applied for an SRM versus an HRE. Because of the more complicated cross-sectional geometry than for the cylindrical grain, the star grain demonstrates more complicated internal ballistic behavior in the two SRMs. The more elaborate behavior is not evident when applying this grain design to the comparable HRE. The profile for the star-grain HRE is similar, and as simple as, the cylindrical HRE case.

\subsection{Wagon-Wheel Grain}

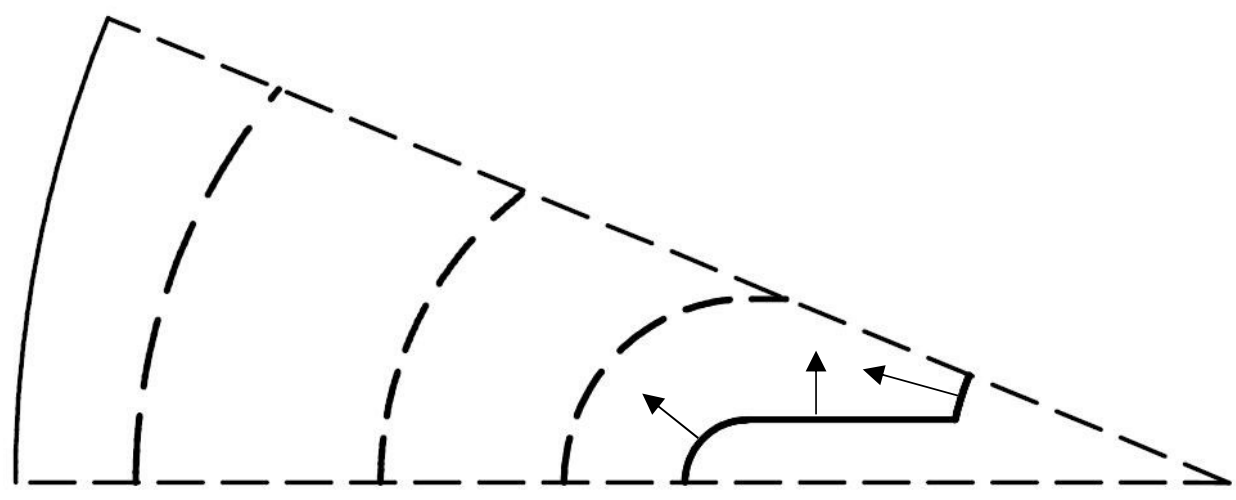

Figure 18 Wagon-Wheel-Grain Cross Section Profile (22.5 Pie Section) with Burn Back

Figure 18 shows the cross section profile $\left(22.5^{\circ}\right.$ pie section) of the wagon-wheel-grain configuration used by the third reference SRM [18]. The diagram illustrates the changing grain profile with burn back. The cross section geometry changing during the firing process is analyzed in Appendix B.

Figures 19 and 20 show the pressure-time profile and thrust-time profile for the wagon-wheelgrain SRM. It shows clearly that the wagon-wheel-grain provides a different internal ballistic behavior relative to the previous two cases. After the beginning of firing, chamber pressure and thrust nonmonotonically decrease until $2.8 \mathrm{~s}$ and then begin increasing until $10.8 \mathrm{~s}$. At this point, both parameters reach the maximum value in the entire firing. The maximum chamber pressure is 5.23 $\mathrm{MPa}$, and the maximum thrust is $9.75 \mathrm{kN}$. This point is also the beginning of the "tail-off" phase. The entire burning process lasts $13.1 \mathrm{~s}$. The internal ballistic behavior of this grain design can be 
described as "regressive-progressive". Initial filling phase aside, the predicted pressure-time and thrust-time profiles agree well with the actual firing data. The total impulse $I_{\text {tot }}$ of this motor is $84835.7 \mathrm{~N} \cdot \mathrm{s}$, and the specific impulse is $210 \mathrm{~s}$.

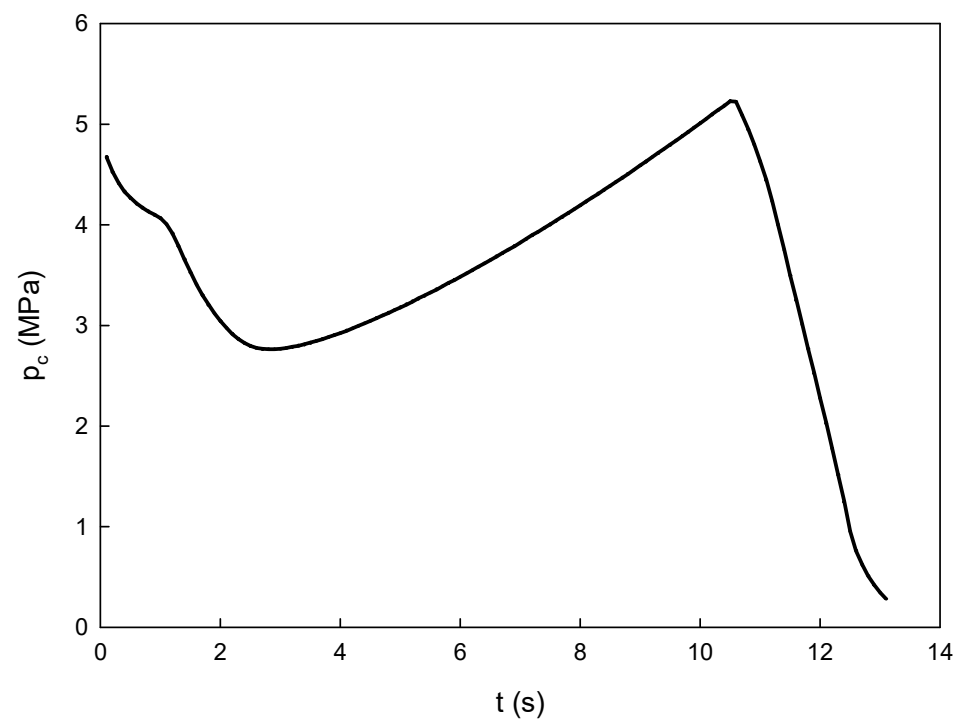

Figure 19 Predicted Pressure-Time Profile for Wagon-Wheel-Grain SRM

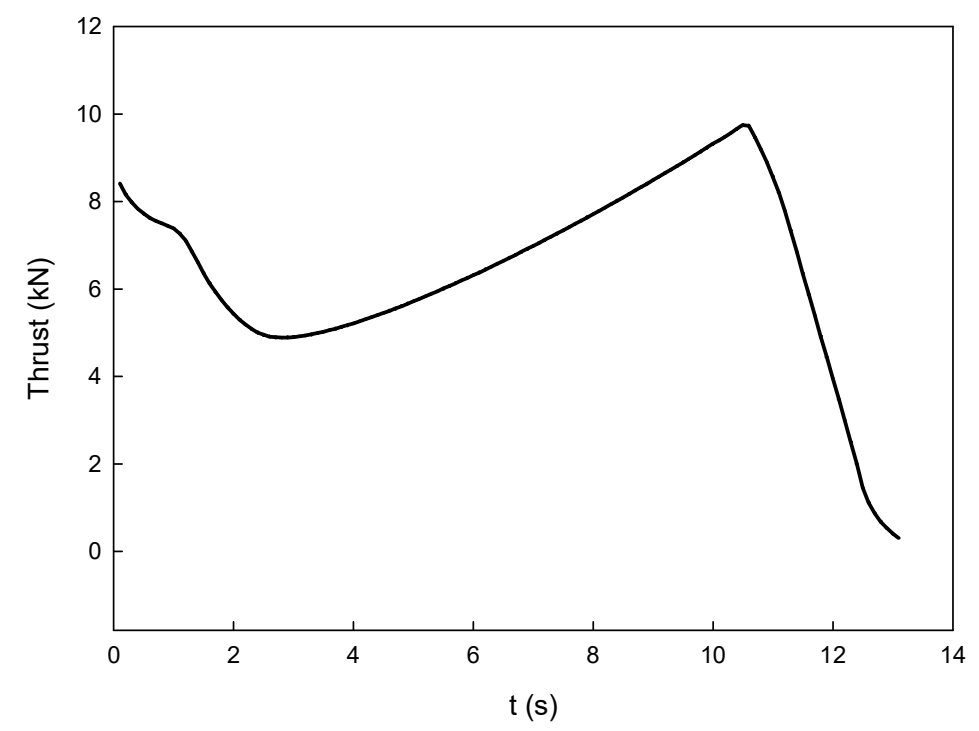

Figure 20 Predicted Thrust-Time Profile for Wagon-Wheel-Grain SRM

Figures 21 and 22 show the pressure-time and thrust-time profile for the wagon-wheel-grain HRE. Chamber pressure and thrust keep decreasing from the start of the main firing phase. The chamber pressure drops from $5.12 \mathrm{MPa}$ to $4.58 \mathrm{MPa}$ while thrust drops from $0.98 \mathrm{kN}$ to $0.87 \mathrm{kN}$. The 
ramping down of both values in the case of the wagon-wheel-grain HRE is more evident, relative to the previous two HREs. The total impulse $I_{\text {tot }}$ of this engine is $38569.8 \mathrm{~N} \cdot \mathrm{s}$, and the specific impulse $I_{s p}$ is $217.5 \mathrm{~s}$.

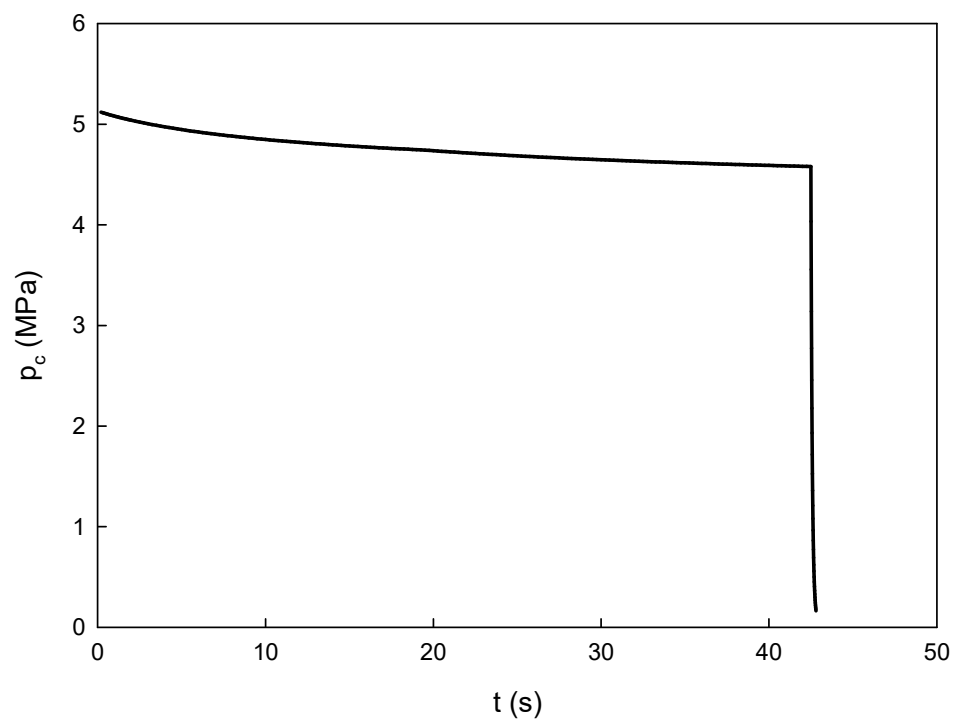

Figure 21 Predicted Pressure-Time Profile for Wagon-Wheel-Grain HRE

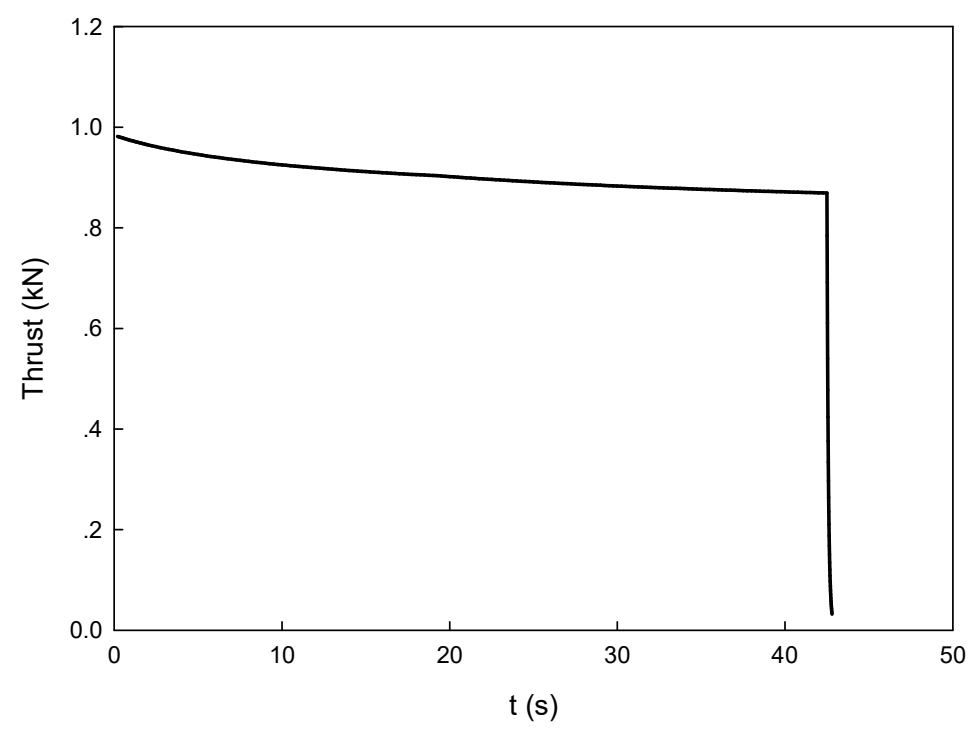

Figure 22 Predicted Thrust-Time Profile for Wagon-Wheel-Grain HRE

Figure 23 shows the stoichiometric length-time profile for the wagon-wheel-grain HRE. Similar to the profiles for the cylindrical and star-grain HREs, the stoichiometric length keeps increasing as the firing progresses. In the case of the wagon-wheel-grain HRE, the value of stoichiometric length is 
pretty low at the beginning. The stoichiometric length starts at $20.13 \%$ and reaches $339.12 \%$ at the end of burning, which illustrates the largest increase in stoichiometric length of the three HREs. Same to the other two grain designs discussed in the present study, the growth rate of stoichiometric length for wagon-wheel-grain HRE also keep decreasing during firing.

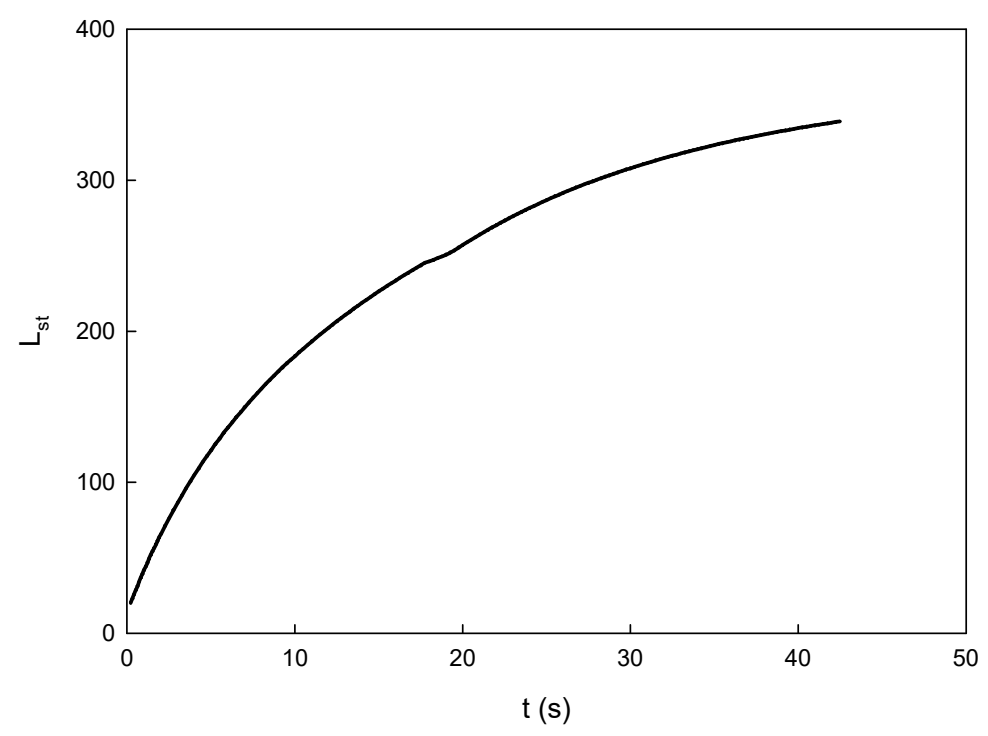

Figure 23 Predicted Stoichiometric Length-Time Profile for Wagon-Wheel-Grain HRE

As another kind of non-cylindrical-grain design, the wagon-wheel-grain also performs differently when applying to an SRM versus an HRE. On the other hand, the profiles for the wagon-wheel-grain HRE are relatively similar to those for the cylindrical and star-grain HRE in qualitative terms.

\subsection{Oxidizer Mass Flow}

From the previous simulations of cylindrical and non-cylindrical-grain HREs, it can be found that no matter what grain designs are applied, the internal ballistic behavior of the three engines are trend-wise relatively similar to each other. All of the three simulations are done under the same oxidizer mass flow. In order to observe the influence of different oxidizer mass flows on the three grain designs, a number of simulations were done, and the results presented in this section.

Figure 24 shows the pressure-time profile for the cylindrical-grain HRE under different oxidizer mass flow rates. This figure clearly shows that with the increasing of the oxidizer mass flow, the 
chamber pressure increases and at the same time the engine's burning period is shorter, which means that with the increasing of the oxidizer mass flow, the burning rate also increases. The pressure keeps dropping slightly from the beginning of firing in all of the five firing simulations, but the larger oxidizer mass flow rates result in a larger pressure drop from beginning to end of the given firing.

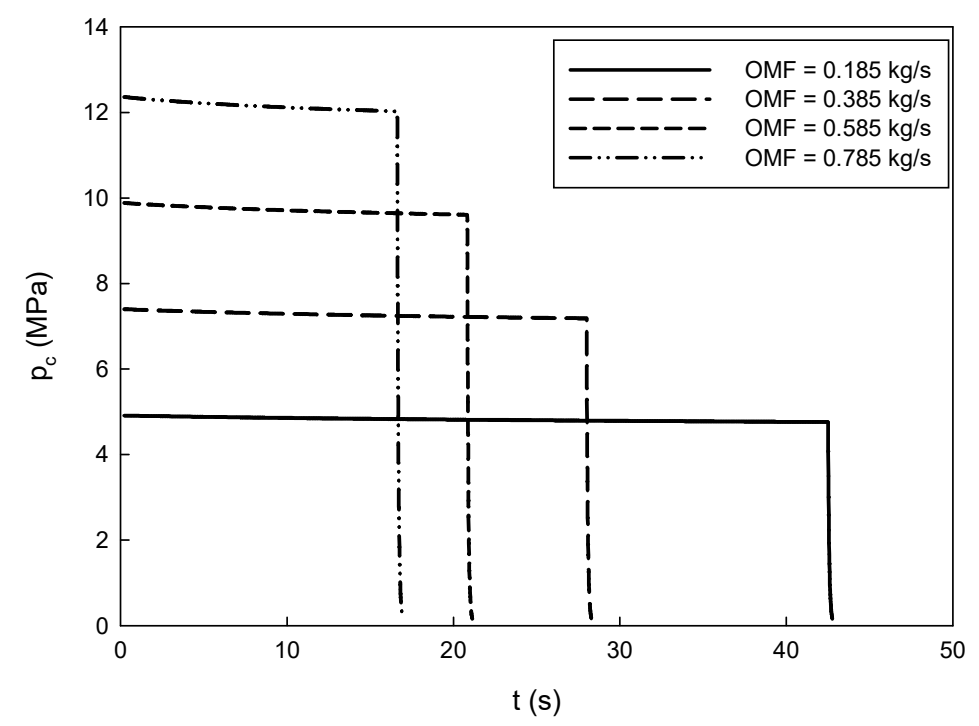

Figure 24 Predicted Pressure-Time Profile for Cylindrical-Grain HRE under Different Oxidizer Mass Flows

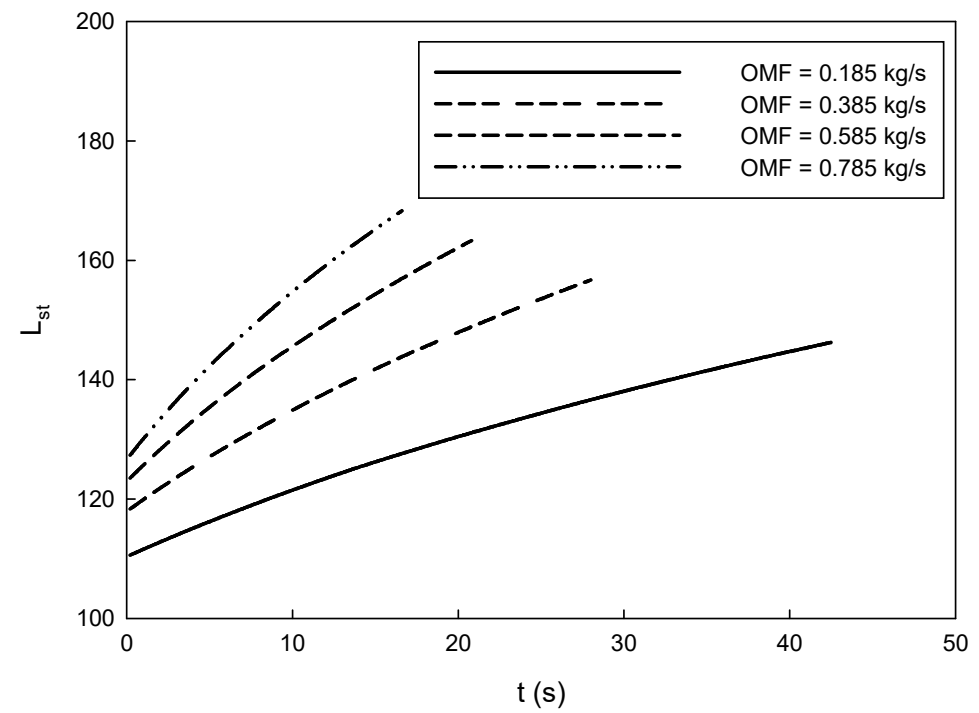

Figure 25 Predicted Stoichiometric Length-Time Profile for Cylindrical-Grain HRE under Different Oxidizer Mass Flows 
Figure 25 shows the stoichiometric length-time profile for the cylindrical-grain HRE under different oxidizer mass flow rates. Table 3 is the stoichiometric length for the cylindrical-grain HRE at the beginning and ending of the firing under different oxidizer mass flows. The figure and the table show that with a larger oxidizer mass flow, the initial and final stoichiometric length for the cylindricalgrain HRE become larger. It can also be concluded that a larger oxidizer mass flow results in a larger increase to stoichiometric length, a larger average rate of growth of the stoichiometric length.

Table 3 Stoichiometric Length for Cylindrical-Grain HRE at Beginning and

Ending of Firing under Different Oxidizer Mass Flows

\begin{tabular}{|c|c|c|}
\hline Oxidizer mass flow & Stoichiometric length at beginning of firing & Stoichiometric length at ending of firing \\
\hline $0.385 \mathrm{~kg} / \mathrm{s}$ & $110.6 \%$ & $146.3 \%$ \\
\hline $0.585 \mathrm{~kg} / \mathrm{s}$ & $118.4 \%$ & $156.8 \%$ \\
\hline $0.785 \mathrm{~kg} / \mathrm{s}$ & $123.5 \%$ & $163.4 \%$ \\
\hline $0.985 \mathrm{~kg} / \mathrm{s}$ & $127.4 \%$ & $168.4 \%$ \\
\hline
\end{tabular}

Figure 26 shows the pressure-time profile for the star-grain HRE under different oxidizer mass flow rates. Similar to the cylindrical-grain HRE, the pressure-time profile qualitatively is not changed much under different oxidizer mass flow rates, keeping the "slightly regressive" profile. The larger oxidizer mass flow rates will also cause a higher chamber pressure, shorter burning period and larger pressure drop from start to finish of the given firing. 


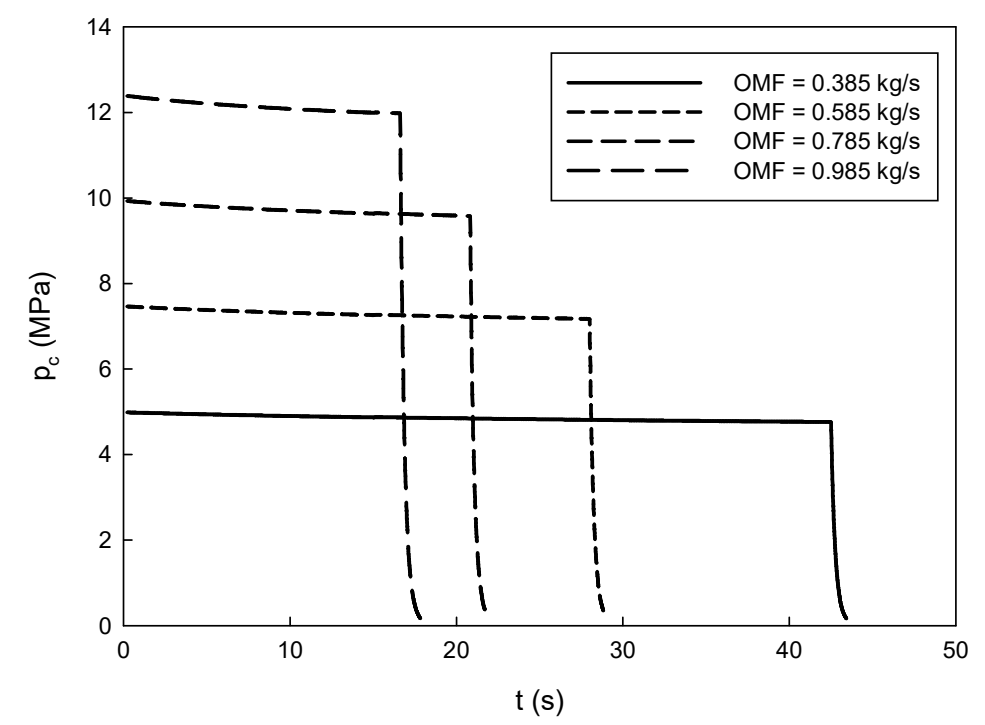

Figure 26 Predicted Pressure-Time Profile for Star-Grain HRE under

Different Oxidizer Mass Flows

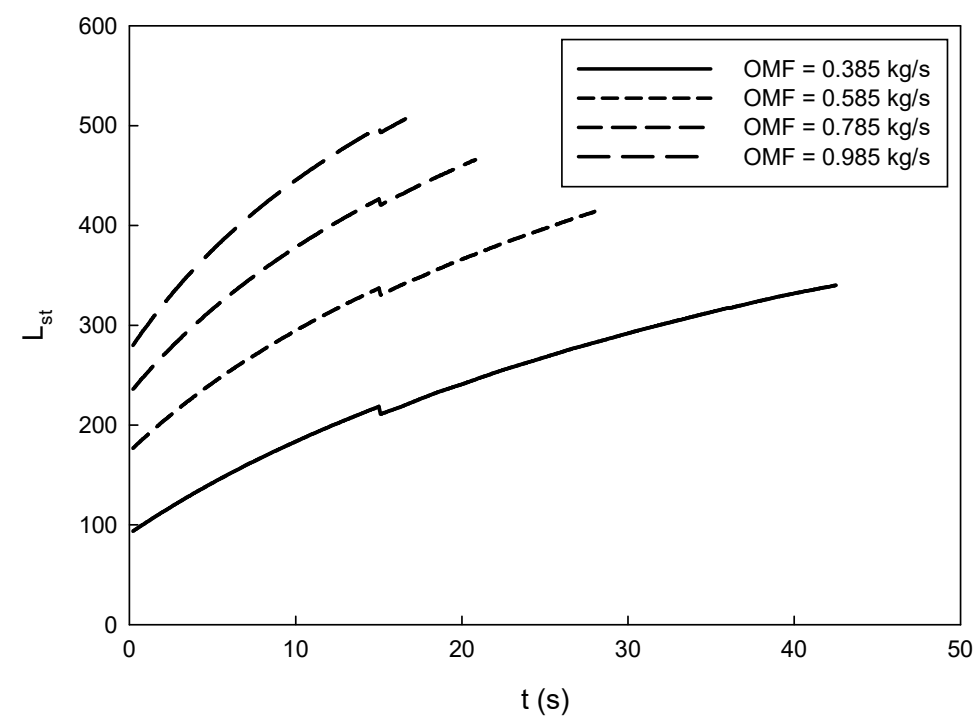

Figure 27 Predicted Stoichiometric Length-Time Profile for Star-Grain HRE under Different Oxidizer Mass Flows

Figure 27 shows the stoichiometric length-time profile for the star-grain HRE under different oxidizer mass flow rates. Table 4 is the stoichiometric length for star-grain HRE at the beginning and the ending of firing under different oxidizer mass flows. Similar to the case of the cylindrical-grain, with a larger oxidizer mass flow, the initial and final stoichiometric length, and the stoichiometric 
length growth rate, for the star-grain HRE, become larger. However, the increase of the stoichiometric length decreases when oxidizer mass flow become larger, which is totally different from the results obtained from the case of the cylindrical-grain HRE.

Table 4 Stoichiometric Length for Star-Grain HRE at Beginning and

Ending of Firing under Different Oxidizer Mass Flows

\begin{tabular}{|c|c|c|}
\hline Oxidizer mass flow & Stoichiometric length at beginning of firing & Stoichiometric length at ending of firing \\
\hline $0.385 \mathrm{~kg} / \mathrm{s}$ & $93.7 \%$ & $340.3 \%$ \\
\hline $0.585 \mathrm{~kg} / \mathrm{s}$ & $176.9 \%$ & $414.2 \%$ \\
\hline $0.785 \mathrm{~kg} / \mathrm{s}$ & $235.9 \%$ & $466.2 \%$ \\
\hline $0.985 \mathrm{~kg} / \mathrm{s}$ & $285.1 \%$ & $507.2 \%$ \\
\hline
\end{tabular}

Figure 28 shows the pressure-time profile for the wagon-wheel-grain HRE under different oxidizer mass flows. The conclusion that can be found from these four burning simulations is similar to the case of the star grain. The change of oxidizer mass flow rate does not influence the general qualitative trend (gentle regressive) pressure-time profile of the wagon-wheel-grain HRE.

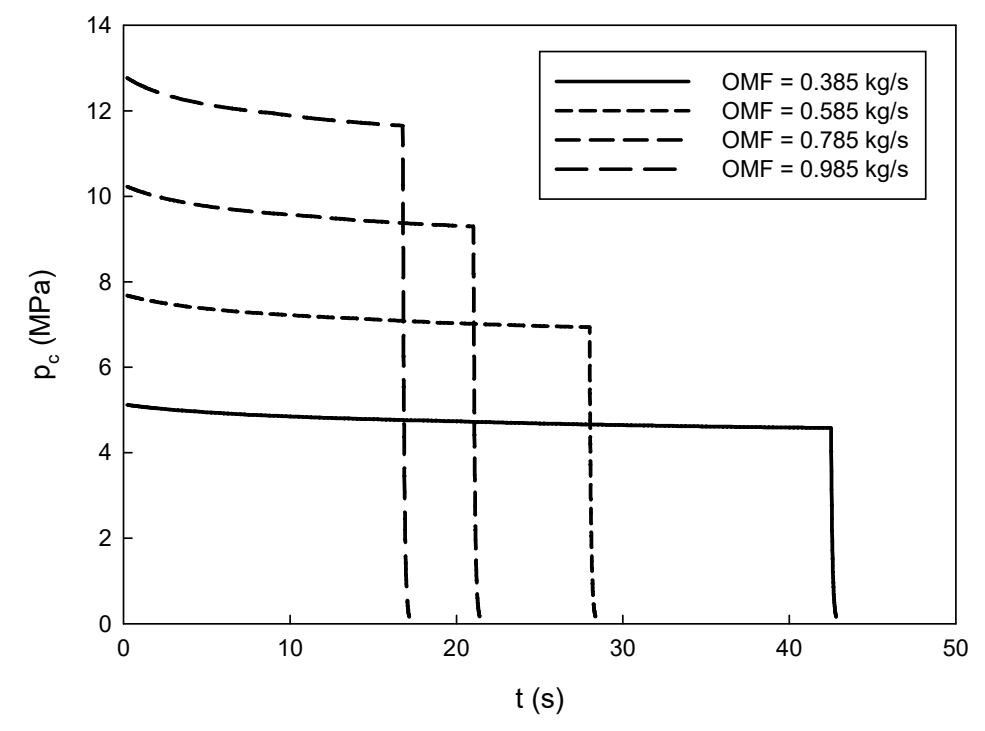

Figure 28 Predicted Pressure-Time Profile for Wagon-Wheel-

Grain HRE under Different Oxidizer Mass Flows 


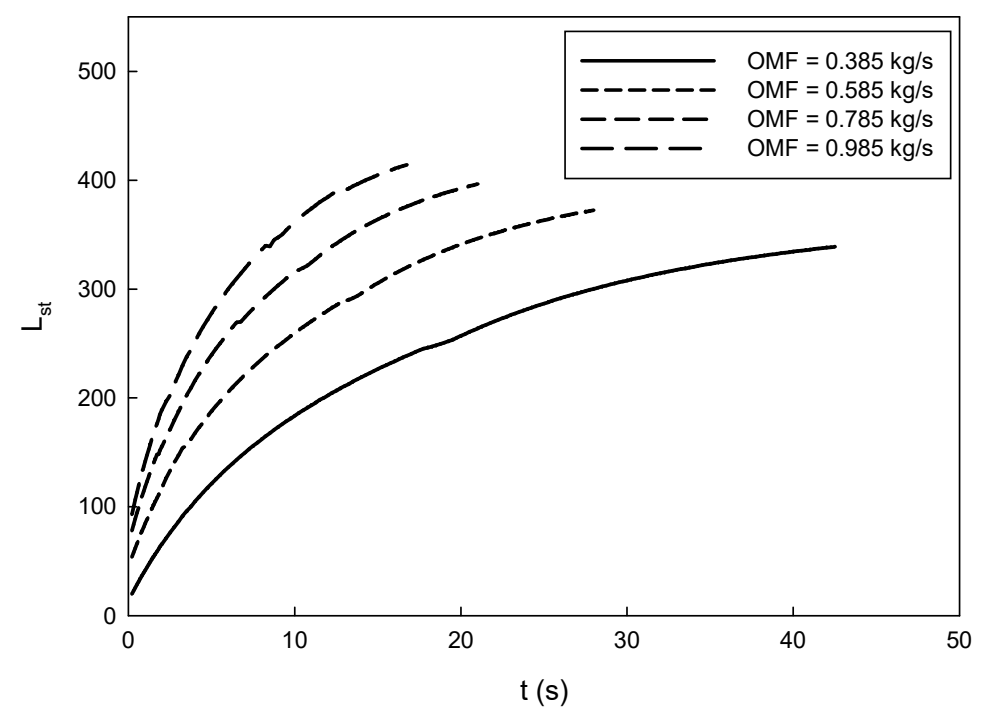

Figure 29 Predicted Stoichiometric Length-Time Profile for Wagon-Wheel-

\section{Grain HRE under Different Oxidizer Mass Flows}

Figure 29 shows the stoichiometric length-time profile for the wagon-wheel-grain HRE under different oxidizer mass flow rates. Table 5 is the stoichiometric length for wagon-wheel-grain HRE at beginning and ending of firing under different oxidizer mass flow. For the case of the wagon-wheelgrain, the qualitative trends of the stoichiometric length-time profile under different oxidizer mass flow are similar to the other two grain design HREs, except for the value of the increase. The increases of the stoichiometric length of wagon-wheel-grain HRE under different oxidizer mass flows are very close to each other, at around $320 \%$.

Table 5 Stoichiometric Length for Wagon-Wheel-Grain HRE at Beginning and

Ending of Firing under Different Oxidizer Mass Flow

\begin{tabular}{|c|c|c|}
\hline Oxidizer mass flow & Stoichiometric length at beginning of firing & Stoichiometric length at ending of firing \\
\hline $0.385 \mathrm{~kg} / \mathrm{s}$ & $20.1 \%$ & $339.1 \%$ \\
\hline $0.585 \mathrm{~kg} / \mathrm{s}$ & $54 \%$ & $372.8 \%$ \\
\hline $0.785 \mathrm{~kg} / \mathrm{s}$ & $78.2 \%$ & $396.7 \%$ \\
\hline $0.985 \mathrm{~kg} / \mathrm{s}$ & $93.2 \%$ & $414.6 \%$ \\
\hline
\end{tabular}

According to the results from the various HRE simulations, it is clear that the oxidizer mass flow 
rate can only influence several performance parameters such as chamber pressure, stoichiometric length and burning period, but cannot affect the qualitative (gentle regressive) trend of the given internal ballistic profile (thrust, pressure).

\subsection{Discussion}

For SRMs, it is obvious that different grain designs can provide quite different internal ballistic behavior. However, for HREs, grain design configurations of the sort looked at in this study do not have as much influence on internal ballistic behavior. Cylindrical and non-cylindrical-grain designs both provide qualitatively similar chamber pressure-time profiles in HREs. All of the three grain configurations produce a higher specific impulse in the HRE than in the corresponding SRM, which in this case proves the better efficiency of hybrid rocket engines.

Although qualitative trends are similar, quantitative differences caused by the HRE grain design can still be identified from the present research. According to the pressure-time profiles coming from the HRE ballistic simulations, the two non-cylindrical-grain HREs always have a higher chamber pressure than the cylindrical-grain HRE, when having the same oxidizer mass flow rate. The chamber pressure of an HRE can be estimated from Eq. (33). In the present study, all three HREs are using the same propellant combination and same oxidizer mass flow rate, which means that in this equation, every parameter except burning area $S$ and port area $A_{p}$ are the same. The star and cylindricalgrain design have very similar inner case diameters, and the wagon-wheel-grain design's inner case diameter is even smaller than the cylindrical-grain design. However, non-cylindrical cross sections have much larger perimeters which result in much larger burning surfaces. Larger burning surfaces are also a means for having a larger amount of fuel that can participate in the burning process. Actually, in the pressure equation for HRE shown above, $\rho_{S} S a\left(\frac{\dot{m}_{O}}{A_{p}}\right)^{n}$ represents the mass flow of the gasified solid fuel. More propellant participating in the burning process will certainly cause higher chamber pressures. With the progression of the firing, grain inner port area $A_{p}$ keeps increasing; this leads to the decreasing of fuel mass flow and finally makes the chamber pressure decrease during burning. This is why, in the end, all of the pressure-time profiles for the HREs are slightly regressive. 
Figure 30 shows the stoichiometric length-time profiles for the three HREs investigated in the present study when the oxidizer mass flow rates for these three engines are all $0.385 \mathrm{~kg} / \mathrm{s}$. It is clear that the two non-cylindrical grain HREs have much higher stoichiometric length for most of the firing time. As mentioned above, stoichiometric length greater than $100 \%$ indicates unreacted oxidizer is entering the nozzle. A large stoichiometric length values above $100 \%$ means that when a hybrid engines is working, a large amount of oxidizer us just going out of the nozzle without attending the combustion process. Because in the present research, all of the three HREs use the same oxidizer/fuel combinations and the masses of oxidizer that are injected to each engine's combustor chamber, are the same $(16.4 \mathrm{~kg})$, a higher stoichiometric length means that less oxidizer ends up reacting with the solid fuel.

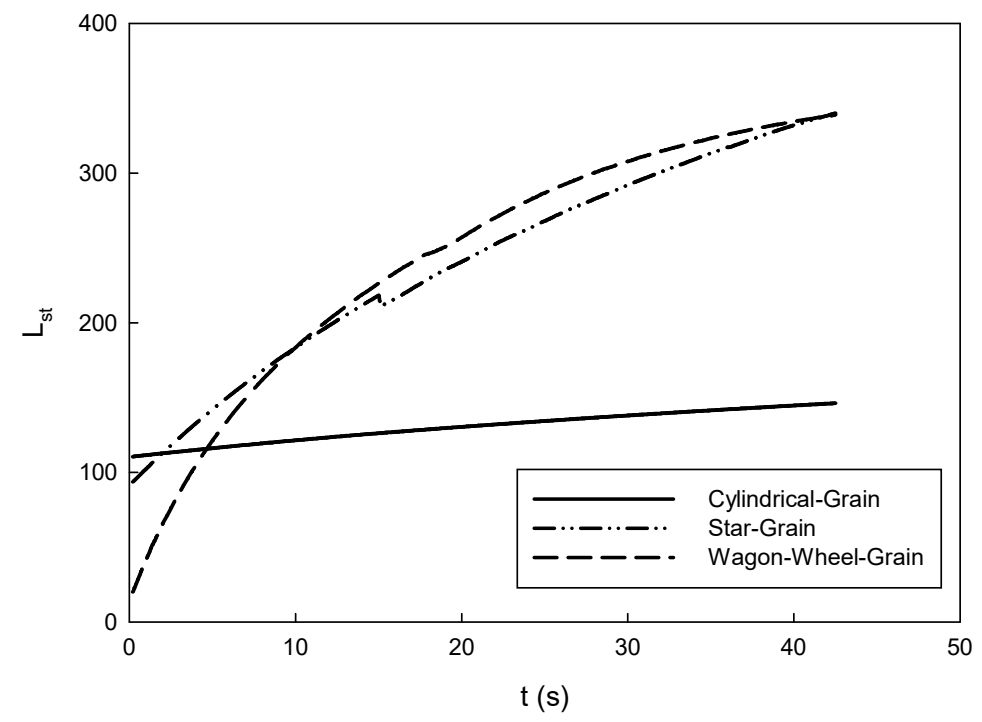

Figure 30 Predicted Stoichiometric Length-Time Profile for the

Three HREs under Same Oxidizer Mass Flows

Overall oxidizer/fuel ratio is the mass ratio of the total oxidizer and fuel that combusts in a given firing. If there is no unreacted oxidizer, the overall oxidizer/fuel ratio should be less than or the same as the stoichiometric mixture ratio (6.5 for the oxidizer/fuel combination used in the three HREs in present study). Figure 31 shows the predicted overall oxidizer/fuel ratio-total oxidizer mass for the three HREs in the present study. The oxidizer mass flow of each engine is $0.385 \mathrm{~kg} / \mathrm{s}$ in the simulations, to get these three curves. This figure shows that, for all of the three HREs, the overall 
oxidizer/fuel ratio increases with the total oxidizer mass's increase. The overall oxidizer/fuel ratio for the wagon-wheel-grain is much higher than the other two HREs. When the total oxidizer mass is low, the overall oxidizer/fuel ratio for the star-grain HRE is lower than for the cylindrical-grain HRE. With the increasing of the total oxidizer mass, the overall oxidizer/fuel ratio for the star-grain HRE becomes larger than for the cylindrical-grain HRE. Considering the much larger solid fuel mass of the star-grain $\operatorname{HRE}(31.3 \mathrm{~kg}$, while for the cylindrical-grain HRE is $6.4 \mathrm{~kg})$, there will be a larger amount of oxidizer needed for the combustion requirements of this engine. For the star-grain HRE, when the total oxidizer mass is $100 \mathrm{~kg}$, the overall oxidizer/fuel ratio increase to 12.35 with $23.2 \mathrm{~kg}$ of unconsumed fuel. When the total oxidizer mass is $150 \mathrm{~kg}$, the overall oxidizer/fuel ratio is 14.16 with $20.7 \mathrm{~kg}$ of unconsumed fuel. It can be assumed from the simulation results above that the overall oxidizer/fuel ratio will keep growing with the increasing of the total oxidizer mass.

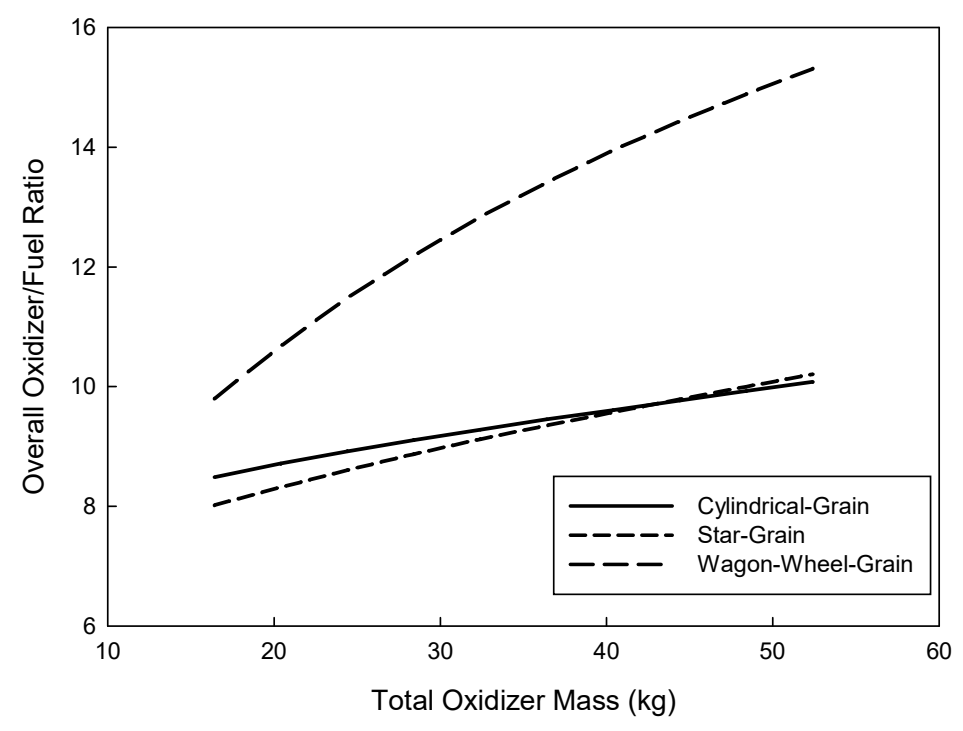

Figure 31 Predicted Overall Oxidizer/Fuel Ratio-Total

Oxidizer Mass Profile for the Three HREs

High overall oxidizer/fuel ratio and stoichiometric length values above their stoichiometric level are not good for the HREs' operational efficiency. Though the specific impulses of the three HREs in present study do not have any significant change with the total oxidizer mass increasing, the specific impulse, and also the efficiency, can be higher if there is not that much oxidizer left unreacted. 


\section{Conclusions and Recommendation for Future Work}

For SRMs, the propellant grain design has a significant influence on the resulting internal ballistic behavior of those motors. Non-cylindrical-grain designs can provide considerable flexibility for design requirements, relative to cylindrical-grain designs. One can commonly set the thrust-time profile that is needed for flight mission requirements by choosing an appropriate non-cylindrical-grain design. On the other hand, there is no obvious qualitative difference in internal ballistic behavior between cylindrical-grain HREs and non-cylindrical-grain HREs of the type investigated here. Both cylindrical and non-cylindrical-grain HREs can deliver thrust stably over a range of thrust values, which is very important for on-command thrust capability. If throttling allowed for the oxidizer delivery, one obviously has further flexibility in controlling the thrust level in-flight (as well as other factors, like stoichiometric length). For a HRE that has its combustion chamber geometry parameters such as solid fuel grain length, chamber wall diameters and inner port diameters already determined, a noncylindrical-grain can provide, however, a larger range and higher level for thrust than that possible via a cylindrical-grain design.

Non-cylindrical-grain HREs have some issues that need to be considered in the design process. As discussed in Section 4.5, there is some space for improving the efficiency of a non-cylindrical-grain HRE. There are several directions that can be investigated in the future, for improving the efficiency further. The oxidizer/fuel combination is probably an aspect that can be looked at, for example. In the present study, all of the three HREs have the same oxidizer/fuel combination. As the propellant type is an important factor that can determine the internal ballistic behavior of a solid rocket motor, the oxidizer/fuel combination is also able to influence a hybrid rocket engine's internal ballistic behavior, for example, in adjusting the stoichiometric length characteristics for a given application. 


\section{Appendices}

\section{Appendix A: Star-Grain Cross-Sectional Geometry Analysis}

Figure 32 shows one of the symmetric $30^{\circ}$ pie sections of the star-grain cross section before burning. As shown in this figure, there are three surfaces, $A, B$ and $C$, on the inner port of this pie section. Surfaces $A$ and $C$ are respectively vertical to the lower boundary and upper boundary of this section. Surface B is parallel to the lower boundary of this section. The length of surface $A$ is $8.7 \mathrm{~mm}$, surface $B$ is $62.5 \mathrm{~mm}$ and surface $C$ is $8.7 \mathrm{~mm}$. The distance from surface $A$ to the center of the grain is $95 \mathrm{~mm}$.

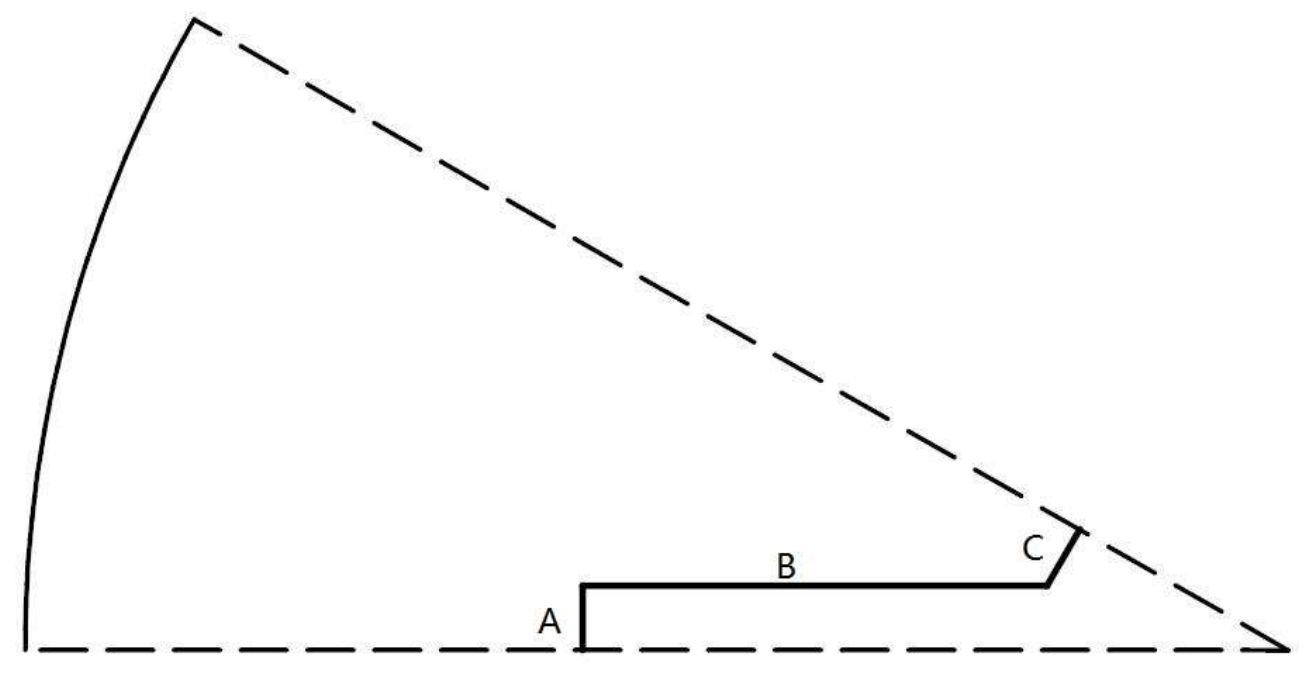

Figure 32 Star-Grain Cross Section (30 Pie Section) before Burning

In the ideal situation, one can assume that the regression direction on every point of the burning surface is perpendicular to the surface. In this star-grain case, this assumption means that with the burning process, the surface A will keep moving to the chamber wall (moving to the left in this figure), surface B will move upward in this figure and surface $C$ will move along the upper boundary of the section in this figure. The corner between surface A and B will form a quadrant surface for which the radius enlarges as per the fuel regression rate. 
At the first phase of burning, with the moving of each surface, the length of surface $A$ will not change. The radius of the quadrant surface between surface A and B will keep increasing. The lengths of surface $B$ and $C$ will decrease. According to the geometrical relationships between each surface and cross section, the decreasing rates of surface $B$ and $C$ will be the same, so surface $B$ will be the first surface to disappear. The regression value when surface $C$ disappear is $l_{C} \cdot \cot 30^{\circ}=15 \mathrm{~mm}$. Here, $l_{C}$ is the length of surface $C$.

After surface $\mathrm{C}$ disappears, the burning process enters the second phase; the cross section at this phase is shown in Figure 33. The length of surface A will not change. The radius of the quadrant surface between surface A and B will keep increasing. The lengths of surface B will decrease. According to the geometrical relationships, when the regression value is $r_{A} \cdot \cot 30^{\circ}-l_{A}=$ $46.15 \mathrm{~mm}$, the length of surface B will decrease to zero. Here, $r_{A}$ is the distance from surface A to the grain center, $l_{A}$ is the length of surface $A$.

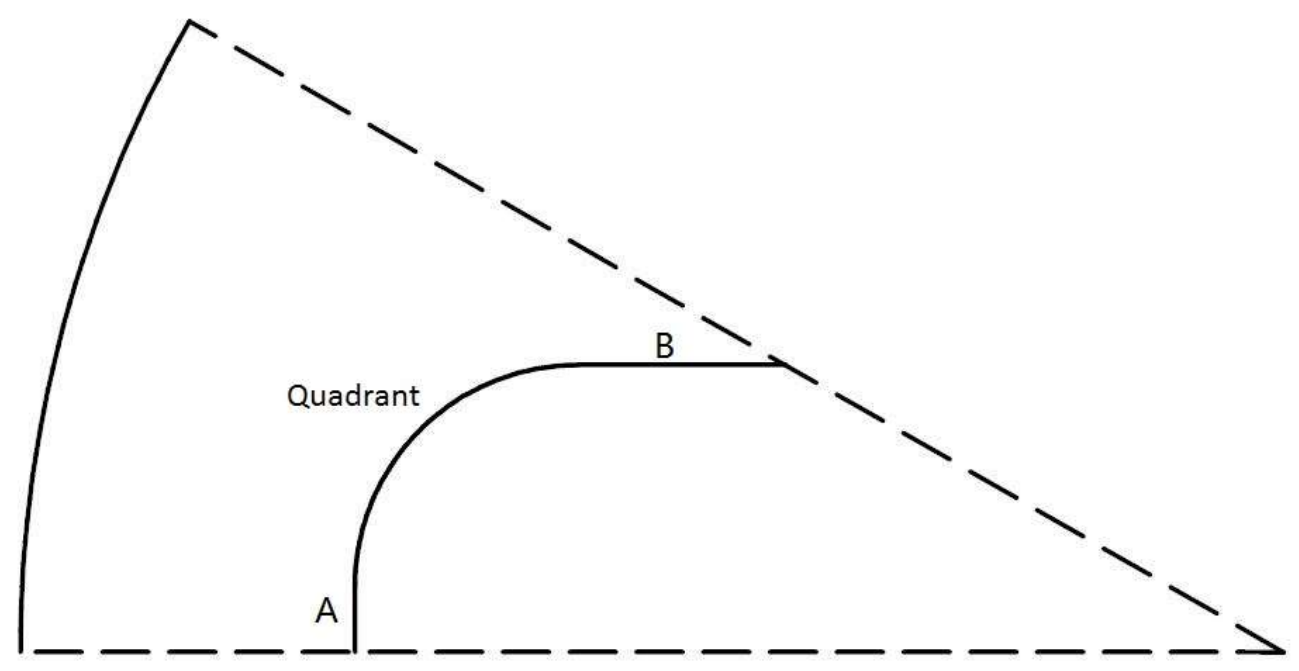

Figure 33 Star-Grain Cross Section (30 Pie Section) in $2^{\text {nd }}$ Phase of Burning

After surface B disappears, the burning process enters the third phase; the cross section at this phase is shown in Figure 34. The length of surface A will not change. The quadrant surface will become an arc surface and the radius of the arc surface between surfaces $A$ and the upper boundary of this section will keep increasing while the central angle corresponding to the arc keeps decreasing. 


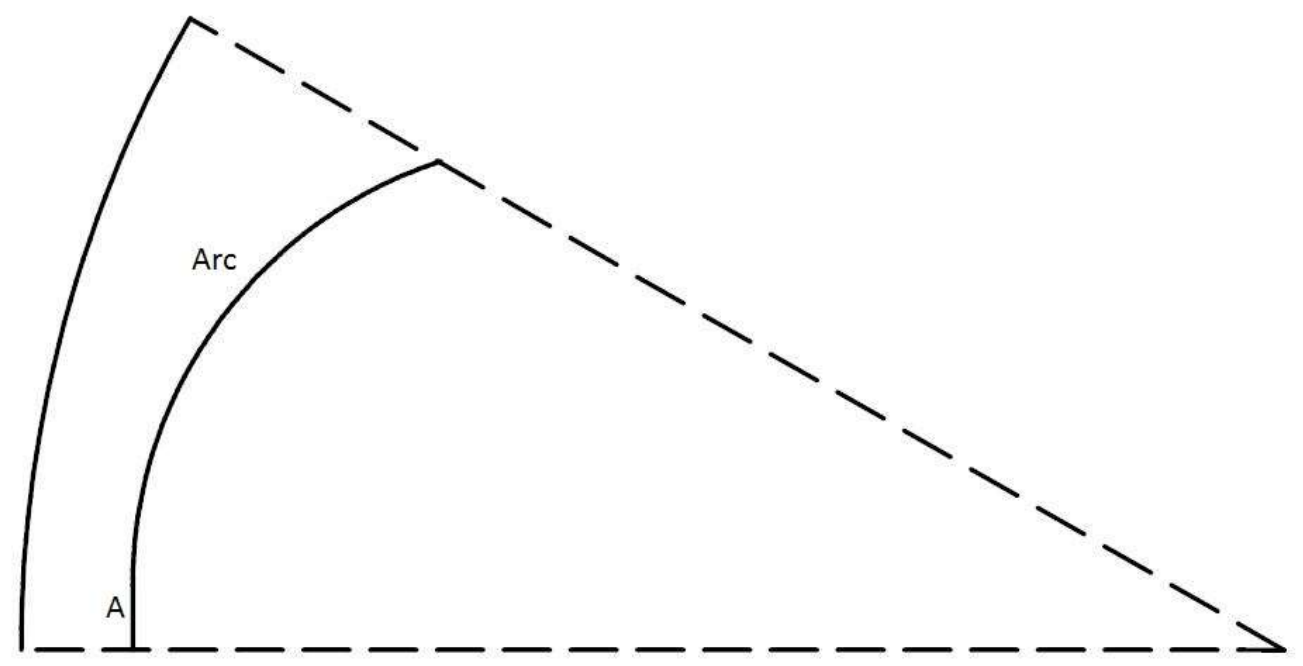

Figure 34 Star-Grain Cross Section (30 Pie Section) in $3^{\text {rd }}$ Phase of Burning

Surface A will keep the length until the cross point of surface $A$ and the arc surface reach the chamber wall. After that the remaining solid propellant or fuel will separate into two parts and burning respectively until all of the propellant or fuel burns out. 


\section{Appendix B: Wagon-Wheel-Grain Cross-Sectional Geometry Analysis}

Figure 35 shows one of the symmetric $22.5^{\circ}$ pie sections of the wagon-wheel-grain cross section before burning. As shown in this figure, there are three surface, $A, B$ and $C$, on the inner port of this pie section. Surface A is a quadrant surface with the radius of $5.2 \mathrm{~mm}$. Surface B is parallel to the lower boundary of this section with the length of $17 \mathrm{~mm}$. Surfaces $C$ is an arc surface with the radius of $23 \mathrm{~mm}$. The distance from the center of surface $A$ to the center of the grain is $39.35 \mathrm{~mm}$ while the center of surface $C$ is the center of the grain.

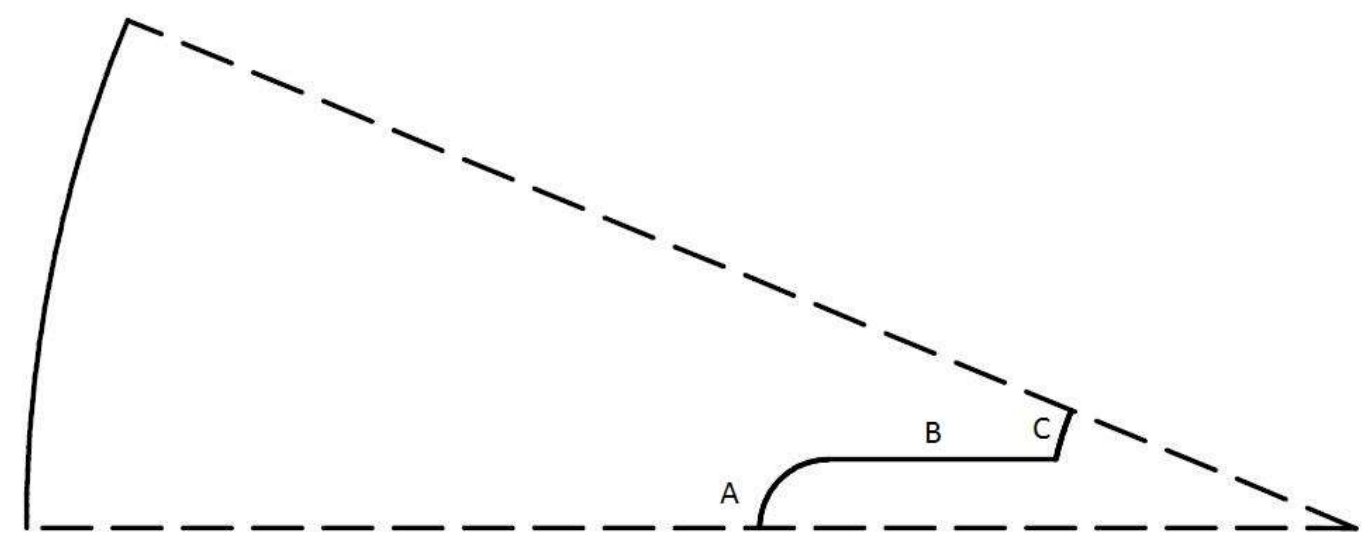

Figure 35 Wagon-Wheel-Grain Cross Section (22.5 ${ }^{\circ}$ Pie Section) before Burning

At the first phase of burning, with the moving of each surface, the radius of surface A will keep increasing. The lengths of surface B will move upward with the length decreasing. Though the radius of surface $\mathrm{C}$ will increase, the central angle corresponding to surface $\mathrm{C}$ will decrease and then cause the arc length of surface $C$ to decrease. The surface $C$ will disappear when the regression value reaches $\frac{r_{C 0} \cdot \sin 22.5^{\circ}-r_{A 0}}{1-\sin .5^{\circ}}=5.8 \mathrm{~mm}$. Here, $r_{C 0}$ and $r_{A 0}$ are the radius of surface $A$ and $C$ before burning.

After surface $\mathrm{C}$ disappears, the burning enters the second phase, the cross section at this phase is shown in Figure 36. The radius of surface A will keep increasing. The length of surface B will keep decreasing. When the regression value is $r_{A c} \cdot \tan 22.5^{\circ}-r_{A 0}=11.1 \mathrm{~mm}$, the surface $\mathrm{B}$ will disappear. Here, $r_{A c}$ is the distance from center of arc surface A to the center of grain. 


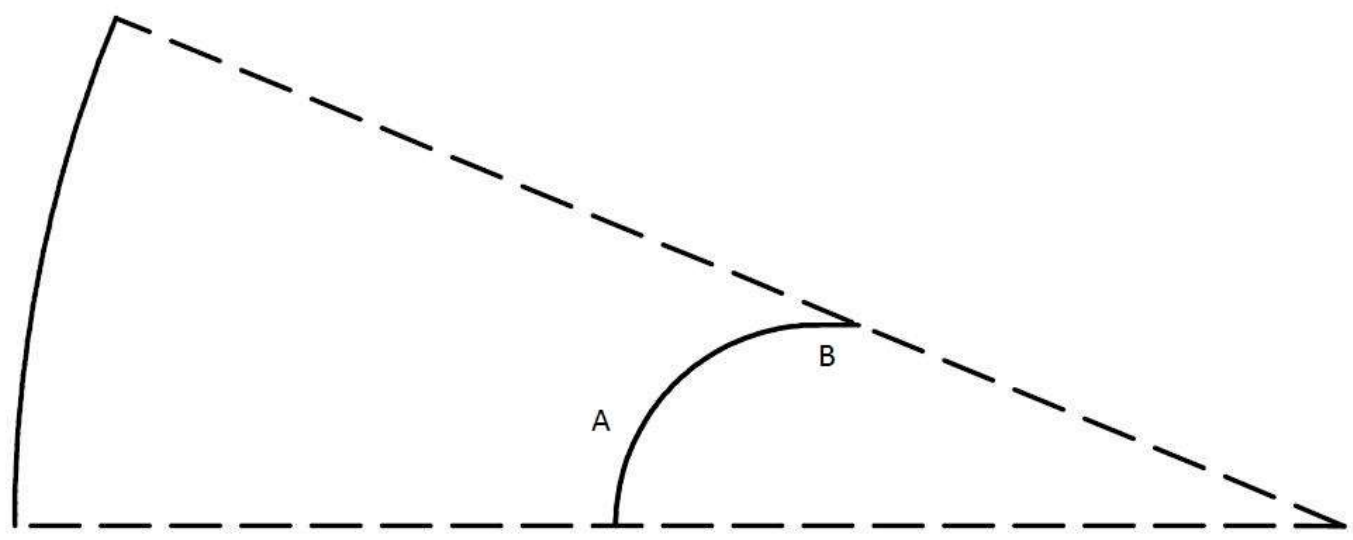

Figure 36 Wagon-Wheel-Grain Cross Section (22.5 $5^{\circ}$ Pie Section) in $2^{\text {nd }}$ Phase of Burning

After surface B disappears, the burning process enters the third phase, the cross section at this phase is shown in Figure 37. The surface A will become an arc surface and the radius of the arc surface will keep increasing while the central angle corresponding to the arc keep decreasing until all of the solid propellant or fuel burns out.

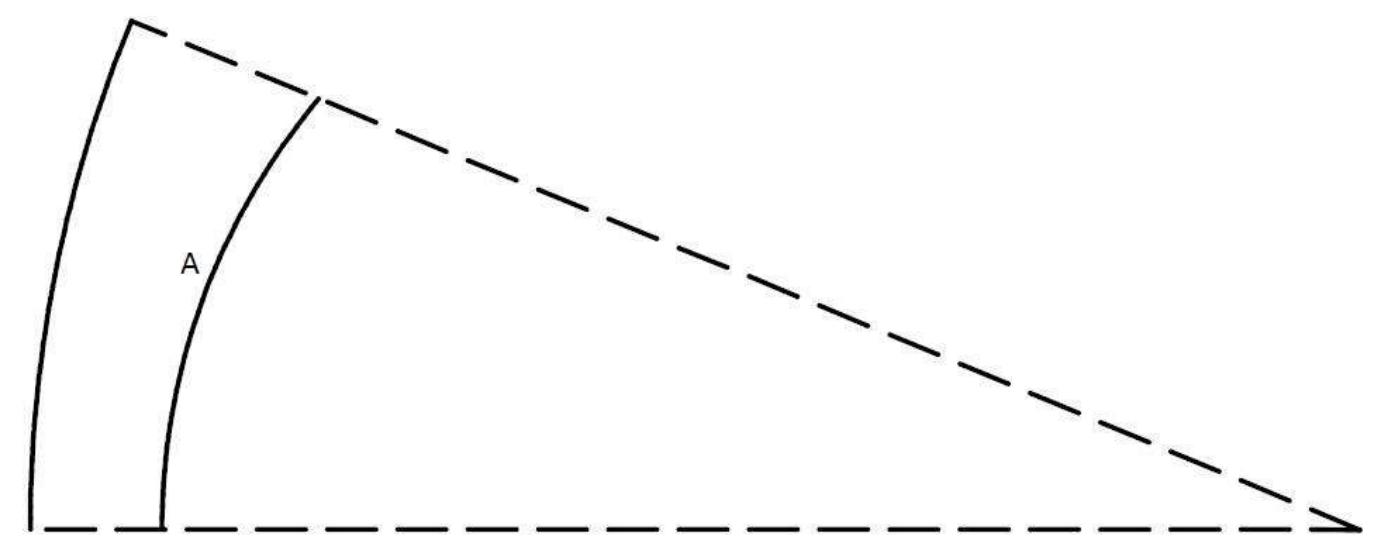

Figure 37 Wagon-Wheel-Grain Cross Section (22.5 $5^{\circ}$ Pie Section) in $3^{\text {rd }}$ Phase of Burning 


\section{References}

[1]. Greatrix D. R. (2009). Regression rate estimation for standard-flow hybrid rocket engines. Aerospace Science and Technology, 13(7), 358-363.

[2]. Greatrix, D. R. (2007). Model for predicting fuel regression rate in hybrid rocket engines. 43rd AIAA/ASME/SAE/ASEE Joint Propulsion Conference \& Exhibit, Joint Propulsion Conferences. AIAA 2007-5346

[3]. Brahmbhatt, V., Greatrix, D.R., Karpynczyk, J. and Trumpour, A.P. (2014). Evaluation of a laboratory-scale hybrid rocket engine's performance. International Journal of Energetic Materials and Chemical Propulsion, Vol. 13, No. 2, 123-139.

[4]. Greatrix D.R. Acceleration-based combustion augmentation modelling for non-cylindrical grain solid rocket motors. AIAA, ASME, SAE, and ASEE, Joint Propulsion Conference and Exhibit, 31st, San Diego, CA; UNITED STATES; 10-12 July 19951995 Jul 10. AIAA 95-2876.

[5]. Greatrix, D.R. (1996). Internal ballistic model for spinning star-grain motors. Journal of Propulsion \& Power, Vol. 12, No. 3, 612-614.

[6]. Greatrix, D. R. (2012). Powered Flight - The Engineering of Aerospace Propulsion, Springer Verlag London.

[7]. Sutton, G. P., \& Biblarz, O. (2001). Rocket propulsion elements book New York: John Wiley \& Sons, Inc.

[8]. Greatrix, D. R., \& Gottlieb, J. J. (1987). Erosive burning model for composite-propellant rocket motors with large length-to-diameter ratios. Canadian Aeronautics and Space Journal, 33, 133-142.

[9]. Mickley, H. S. (1954). Heat, mass, and momentum transfer for flow over a flat plate with blowing or suction. Washington, D.C: National Advisory Committee for Aeronautics, Technical Note 3208. 
[10]. Kays, W. M., Moffat, R. J., \& Thielbahr, W. H. (1970). The turbulent boundary layer on a porous plate - experimental heat transfer with uniform blowing and suction, with moderately strong acceleration (heat transfer to transpired turbulent boundary layer on porous plate with moderately strong acceleration). (No. NASA-CR-109866; SU-HMT-11; Pagination 37P).

[11]. Munson, B. R., Young, D. F., \& Okiishi, T. H. (2006). Fundamentals of fluid mechanics. Hoboken, NJ: J. Wiley \& Sons.

[12]. Greatrix, D. R. (2006). Model for prediction of negative and positive erosive burning. Can Aeronaut Space J 53:13-21.

[13]. Greatrix, D. R. (1987). A Study of Combustion and Flow Behavior In Solid-propellant Rocket Motors (Order No. NL39756). Available from ProQuest Dissertations \& Theses A\&I: Science \& Technology; ProQuest Dissertations \& Theses Global: Science \& Technology. (303651175)

[14]. Marxman, G. A. (1965). Combustion in the turbulent boundary layer on a vaporizing surface (turbulent boundary layer combustion on vaporizing surface considering heat transfer, mass transfer and chemical reactions). SYMPOSIUM /INTERNATIONAL/ ON COMBUSTION, 10TH, U.OF CAMBRIDGE, CAMBRIDGE, ENGLAND; United States; 17-21 Aug.1964 pp. 1346-1349.

[15]. Davydenko, N. A., Gollender, R. G., Gubertov, A. M., Mironov, V. V., \& Volkov, N. N. (2007). Hybrid rocket engines: The benefits and prospects. Aerospace Science and Technology, 11(1), 55-60.

[16]. William H. Knuth, Martin J. Chiaverini, J. Arthur Sauer, and Daniel J. Gramer. (2002) Solid-Fuel Regression Rate Behavior of Vortex Hybrid Rocket Engines, Journal of Propulsion and Power, Vol. 18 , No. 3, 600-609.

[17]. Jackson, F., Christie, F.A., Clark, M.N., Duchesne, G.L., Morris, E.P., Smith, D.L., and Bergman, W.A. (1976) An Improved Canadian 2.75-Inch Rocket Motors. Institute of Aeronautics and Astronautics and Society of Automotive Engineers, Propulsion Conference, 12th, Palo Alto, Calif.; United States; 26-29 July 1976. AIAA Paper No. 76-713. 
[18]. Carrier, J. L. C., Constantinou, T., Harris, P. G., \& Smith, D. L. (1986). The dual-interruptedthrust pulse motor. Journal of Propulsion and Power, Vol. 3, No. 4 (1987), pp. 308-312

[19]. Lucy M.H. (1968) Spin Acceleration Effects on Some Full-Scale Rocket Motors. Journal of Spacecraft and Rockets Vol. 5:179-183. 